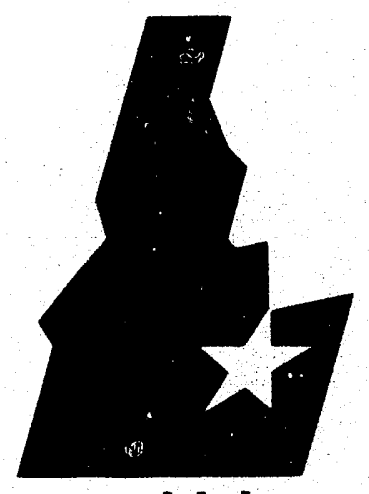

Idaho National

Engineering

Laboratory

Managed

by the U.S.

Department

of Energy

EGG-EP-9885

OCTOBER 1991

INFORMAL REPORT

\title{
LABORATORY TESTING OF HIGH ENERGY DENSITY CAPACITORS FOR ELECTRIC VEHICLES
}

A. F. BURKE

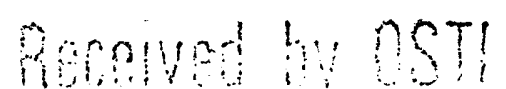

NOY 2 ב 1991

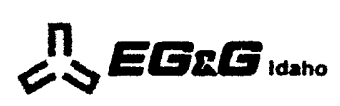

Work performed under DOE Contract No. DE-ACO7-76IDO1570 
This document contains new concepts or the author(s) interpretation of new calculations and/or measurements; accordingly, EG\&G Idaho, Inc. is required by the United States Government to include the following disclaimer:

\section{DISCLAIMER}

This report was prepared as an eccount of work sponsored by an agency of the United States Govemment. Neither the LInited States Government nor any agency thereof, nor any of thoir employees, makes any warranty, oxpress or implied, or assumes amy logal liability or responslbilty for the eccurscy. completeness, or usofulnoss of any intormation, epparatus, product or process cisclosed, or represents thet its use would not infringes privatoly owned riohts. Reterences herein to any spectic commercial product, proceses, of earvice by trade name, tredemark, manulacturer, or othenvise, does not necsesently constitute or imphy its endorsement, recommendation, or favoring by the United States Govemment or any egency thereof. The views and opinions of authors expreased horein do not necesenrily state or reflect those of the United States Covernment or any apency thereof. 
EGG-EP- -9885

DE 92003385

\section{IABORATORY TEBTING OF HIGH ENERGY DENSITY CAPACITORB FOR \\ ELECTRIC VEHICLES}



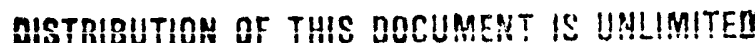




\section{SUMMARY}

Laboratory tests of advanced, high energy density capacitors in the Battery Test Laboratory of the Idaho National Engineering Laboratory have been performed to investigate their suitability for load-leveling the battery in an electric vehicle. Two types of devices were tested- $3 \mathrm{~V}, 70$ Farad, spiral wound, carbon-based, single cell devices obtained from Japan and 20 V, 3.5 Farad, mixed-oxide, multi-cell bipolar devices purchased from Pinnacle Research Institute, Cuppertino, California. The energy density of the devices, based on energy stored during charge to the rated voltage, was found to be $1-2 \mathrm{Wh} / \mathrm{kg}$, which agreed well with that claimed by the manufacturers. Constant power discharge tests were performed at power densities up to $1500 \mathrm{~W} / \mathrm{kg}$. Discharges at higher power densities could have been performed had equipment been available to maintain constant power during discharges of less than one second. It was found that the capacitance of the devices were rate dependent with the rate dependency of the carbon-based devices being higher than that of the mixed-oxide devices. The resistances of both types of devices were relatively low being 20-30 milliohms.

Testing done in the study showed that the advanced high energy density capacitors can be charged and discharged over cycles (PSFUDS) which approximate the duty cycle that would be encountered if the devices are used to load-level the battery in an electric vehicle. The test data indicate that the useful energy from the device when it is operated between rated and one-half rated voltage is about one-half that stored in the capacitor when it is charged from $0.0 \mathrm{~V}$ to the rated voltage. This is less than would be expected because the capacitance of the device is rate dependent and round-trip efficiencies of the present devices are $75-85 \%$. Thermal tests of the advanced capacitors in an insulated environment using the PSFUDS cycle showed the devices do not overheat with their temperatures increasing only $4-5^{\circ} \mathrm{C}$ for tests that lasted 5-7 hours. Life cycle tests of the Japanese capacitors showed a cycle life in excess of one hundred thousand charge/discharge cycles. Tests of the PRI capacitors indicated a shorter cycle life of about thirty thousand cycles.

The performance characteristics of the advanced capacitors tested in the present study were compared with those of commercially available supercapacitors 
from NEC Electronics and with the minimum requirements for electric vehicle applications (see the Summary Table). It was found that the energy densities of advanced capacitors are a factor of 3-10 higher than that of the NEC Supercap and that the resistances of the advanced capacitors are much lower (several orders of magnitude) than that of the Supercap devices. The energy density of the NEC Supercaps is 1-2 orders of magnitude higher than that of low voltage, electrolytic capacitors, so that the energy density of the advanced capacitors represents a very large increase over that expected of capacitors in the past. A further increase in energy density of at least a factor four (4) is required to meet the goal of $5 \mathrm{Wh} / \mathrm{kg}$ needed for electric vehicle applications. The challenge of future capacitor development will be to achieve at least $5 \mathrm{Wh} / \mathrm{kg}$ and at the same time maintain an acceptably low resistance. Projections of future development given in the literature for mixed-oxide ultracapacitors indicate that the performance goals can be met and surpassed in a few years. Meeting the 5 Wh/kg goal for carbon-based capacitors is expected to be more difficult, but the cost of carbon-based devices is at the present time projected to be much less (at least a factor of ten) than that of the mixed-oxide capacitors, which presently utilize ruthenium and tantalum oxides as key materials. If substitution of lower cost materials in the mixed-oxide devices proves feasible, then those devices would seem to offer the best prospects for high energy density capacitors to load-level the battery in electric vehicles. 


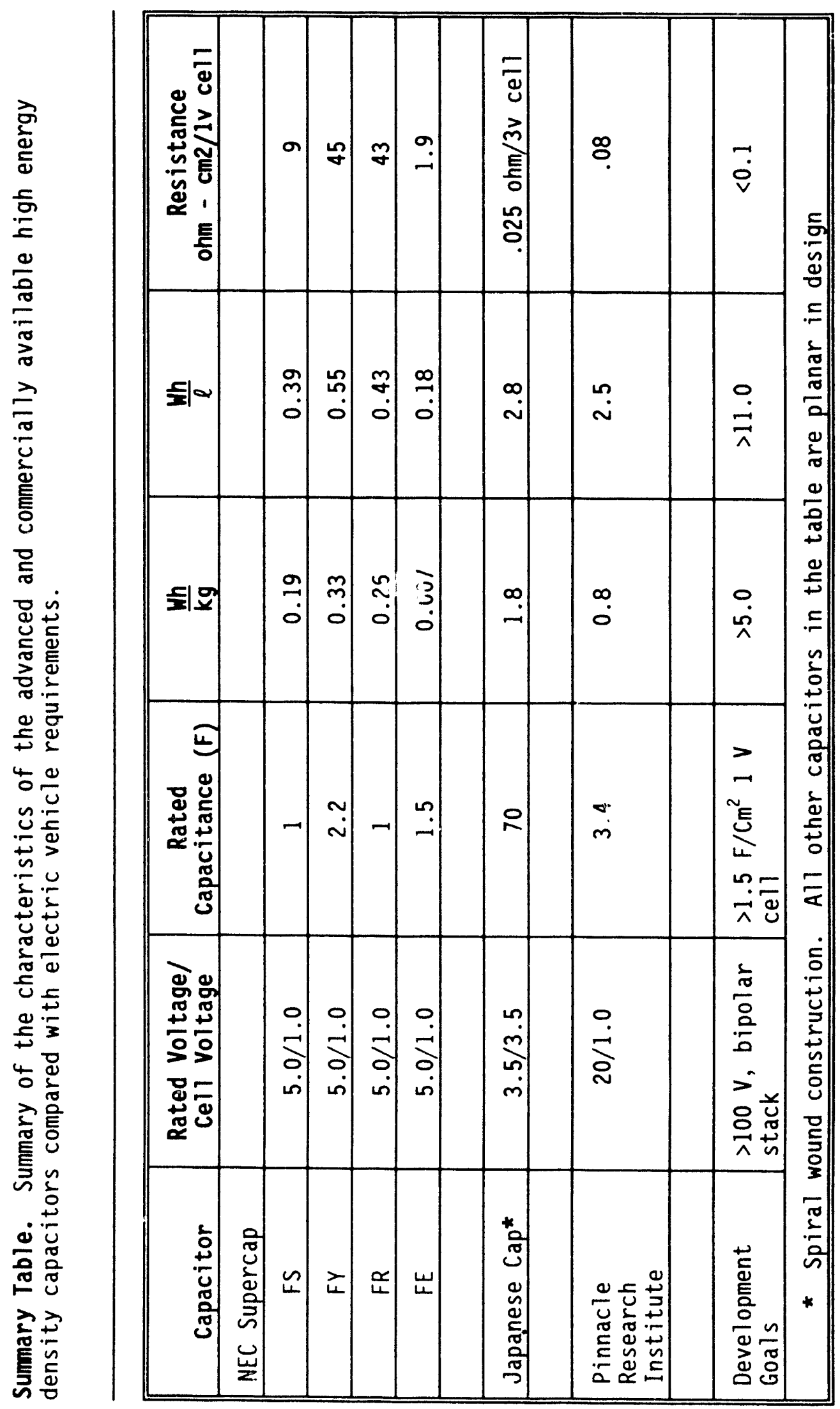




\section{ACKNOWLEDGMENT}

Acknowledgment and special thanks are expressed to the following individuals who assisted in the preparation of this report and performed the testing in the INEL Battery Laboratory:

- E. J. Dowgiallo and P. A. Brookshier of the U.S. Department of Energy for their support.

- G. L. Hunt and P.Y. Smith for editorial and publication assistance.

- J. E. Hardin, and E. M. Martin for battery testing, data reduction, and analysis. 


\section{CONTENTS}

Summary .. . . . . . . . . . . . . . . . . . . . . i i i

Acknowledgements ...................... vii

Introduction . . . . . . . . . . . . . . . . . . . . . . . . . . . . . . 1

Application of Capacitors for Battery Load Leveling in Electric Vehicles . 3

Capacitor Devices . . . . . . . . . . . . . . . . . . 9

Test Equipment and Procedures . . . . . . . . . . . . . . . . 13

Test Equipment ..................... 14

Battery Test Cycler .................. 14

Environmental Chamber and Thermal Test Set-Up . . . . . 16

Life Cycle Test Set-Up . . . . . . . . . . . . . . . 16

Test Procedures . . . . . . . . . . . . . . . . . . 19

Device Characterization Tests . . . . . . . . . . 19

PSFUDS (variable power) Tests ............ . 20

Life Cycle Tests . . . . . . . . . . . . . . 22

Thermal Response Tests ................. 24

Test Results . . . . . . . . . . . . . . . . . . . . 25

The Japanese Capacitor . . . . . . . . . . . . . . . . 25

Performance Characteristics . . . . . . . . . . . 25

PSFUDS Cycle ................... 30

Life Cycle Test . . . . . . . . . . . . . . 40

Thermal Response Tests .. . . . . . . . . . . . . 40

The Pinnacle Research Institute Capacitor . . . . . . . . . . 47

Performance Characteristics . . . . . . . . . . . . 47

PSFUDS Cycle ................... 58

Life Cycle Tests ................. 66

Thermal Response Tests . . . . . . . . . . . . . 66

The Status of High Energy Density Capacitor Technology . . . . . . . . 69

Conclusions and Recommendations For Future Work . . . . . . . . . . . . 73

Conclusions .................... 73

Recommendations .................... 74

References . . . . . . . . . . . . . . . . . . . 75 


\section{FIGURES}

1. Schematic of an electric vehicle propulsion system, including battery load leveling

2. The effect of the ultracapacitor on the battery power profile on the fUDS cycles . . . . . . . . . . . . . . . . . . 5

3. The Japanese Capacitor in the test set-up ............ 10

4. Photograph of a Pinnacle Research ultracapacity (3" dia.) .... 11

5. Photo of bitrode ..................... 15

6. Photo of thermal test enclosure ................ 17

7. Schematic of the life-cycle test set-up and circuit . . . . . . . . 18

8. Current and voltage traces for the Japanese Capacitor on the PSFUDS cycle ....................... 23

9. Photograph of the capacitor test set-up with the data acquisition computer . . . . . . . . . . . . . . . . 26

10. Charging characteristic of the Japanese Capacitor at several charging currents . . . . . . . . . . . . . . . . 27

11. Discharge characteristics of the Japanese capacitor at various constant powers . . . . . . . . . . . . . . . . . . 28

12. Rate dependency of the energy and charge capacity of the Japanese Capacitor for discharge at various constant power densities . . . . 29

13. Voltage decay characteristic of the Japanese Capacitor after charging to $3 \mathrm{~V}$. . . . . . . . . . . . . . . . . 32

14. Recovery after discharge .................. 33

15. Power profile for the Japanese Caparitor on the PSFUDS cycle . . . 34

16. Voltage versus time traces for early cycles of the Japanese Capacitor on an extended PSFUDS test . . . . . . . . . . . . 36

17. Voltage versus time traces for late cycles of the Japanese Capacitor on an extended PSFUDS test . . . . . . . . . . . 37

18. Current versus time traces for early cycles of the Japanese Capacitor on an extended PSFUDS test . . . . . . . . . . . . . 38

19. Current versus time traces for late cycles of the Japanese Capacitor on an extended PSFUDS test . . . . . . . . . . . . 39

20. A strip-charge record of voltage versus time during charge/discharge cycles of the Japanese Capacitor after about 80,000 cycles 
21. Temperature traces during the heat-loss calibration of the insulated enclosure placed in the environmental chamber . . . . 45

22. Charge versus voltage characteristic of the PRI Capacitor . . . . 48

23. Charge versus voltage characteristics of the PRI Capacitor for various constant power discharges ............. 51

24. Rate dependency of the energy and charge capacity of the PRI Capacitors for discharge at various constant power densities . . . 52

25. Hysterisis in $Q$ versus $V$ plot for the PRI Capacitor . . . . . . 54

26. Hysterisis in the $Q$ versus $V$ plot for the Japanese Capacitor . . . 55

27. Comparison of the rate dependency in discharge of the Japanese and PRI Capacitors ................ 56

28. Resistance of the Japanese and PRI Capacitors as a function of frequency ................ . . . . . . . 57

29. Voltage decay of the PRI Capacitor after a $2 A$ charge to $20 \mathrm{~V}$. . . 59

30. Voltage recovery of the PRI capacitor after a discharge to $0.0 \mathrm{~V} \quad 60$

31. Load sharing between two PRI Capacitors during a PSFUDS test (Cycle 5) ..................... 62

32. Load sharing between two PRI Capacitors during a PSFUDS test (Cycle 50) .................... 63

33. Load sharing between two PRI Capacitors during a PSFUDS test (Cycle 150)

\section{TABLES}

Table 1. Capacitor specification for electric vehicle applications . . 6

Table 2. Power profile for the PSFUDS test cycle . . . . . . . . 21

Table 3. The dc resistance of the Japanese capacitors calculated from constant current charge/discharge data . . . . . . . 31

Table 4. Change in characteristics of the Japanese capacitor during the life cycle test ................. 42

Table 5. Thermal chamber calibrat: on data and analysis ...... . 44

Table 6. Summary of the thermal test and efficiency results for the Japanese capacitor .. . . . . . . . . . . . . . . 46

Table 7. PRI capacitance in Farads ............... . 49

Table 8. Variability of the PRI devices . . . . . . . . . . . 50 
Table 9. Temperature increase of the PRI devices during a long PSFUDS test ................... 65

Table 10. Summary of thermal test and efficiency results for the PRI Capacitor .................. . . 67

Table 11. Comparison of the characteristics of the advances and commercially available high energy density capacitors . . 70 


\section{LABORATORY TESTING OF HIGH ENERGY DENSITY CAPACITORS FOR ELECTRIC VEHICLES}

\section{INTRODUCTION}

The discharge profile (power vs. time) required from the battery in an electric vehicle is highly variable showing high peaks of power both in and out of the battery. The time durations of these peaks in urban driving are as short as a few seconds and as long as 20-30 seconds. Studies (References 1 and 2) have been made at the Idaho National Engineering Laboratory (INEL) to investigate whether high energy density capacitors could be utilized to provide the peak power demands allowing the vehicle battery to supply the average power needed by the vehicle. The capacitors would be recharged from the battery during periods of low power demand. The INEL studies indicated that a minimum energy density of about $5 \mathrm{Wh} / \mathrm{kg}(18 \mathrm{~J} / \mathrm{gm})$ was required before capacitors could be seriously considered for inclusion in an electric vehicle driveline to load isvel the battery. At the present time (earl; 1990s) the highest energy density capacitors available have an energy density of 1-2 Wh/kg. These capacitors are often referred to as supercapacitors or ultracapacitors, because their energy density is much higher than that of conventional capacitors which have an energy density of less than $0.15 \mathrm{Wh} / \mathrm{kg}$.

This report is concerned with testing two high energy density capacitors utilizing test equipment and procedures that are especially suited to electric vehicle applications. The ubjective of the testing was to determine the present state-of-the-art of high energy density capacitors in relation to the requirements for devices for use in electric vehicle drivelines. 


\section{APPLICATION OF CAPACITORS FOR BATTERY LOAD LEVELING IN ELECTRIC VEHICLES}

The average power that must be supplied by the battery in an electric vehicle is relatively low $(10-30 \mathrm{~W} / \mathrm{kg})$ depending on the driving mode and grade. The peak power pulses of relatively short duration are much higher $(80-100 \mathrm{~W} / \mathrm{kg})$. The battery must be designed to supply both the required energy ( $k W h$ ) and the peak power (KW) if the vehicle is to meet its range and acceleration goals. The battery energy density and peak power density requirements can be decoupled if the battery is load leveled using a peak power device (see Figure 1 for a driveline schematic), which can meet the peak power demands.

Various aspects of battery load leveling in electric vehicles are discussed in detail in References 1-3. The effect of battery load leveling on the battery power profile for a minivan on the FUDS cycle is shown in Figure 2. It is clear from the figure that the high power transients can be transferred to the capacitor with the battery supplying nearly constant power over the driving cycle. Since capacitors have very high power capability and long cycle life for rapid, deep discharges, the primary limitation on their use in this electric vehicle application is their low energy density, which limits the energy that can be stored in a weight and volume that is practical for a vehicle. Computer simulations (Reference 3 ) of vehicles utilizing the hybrid electric driveline shown in Figure 1 indicate that a capacitor energy storage of 300-500 Wh is needed to load level the battery on the FUDS cycle. This results in the capacitor performance specifications shown in Table 1. There are no capacitor devices available at the present time that have an energy density as high as $5 \mathrm{Wh} / \mathrm{kg}$. The two devices procured for testing in this study have the highest energy density of any known to be available at the present time. The capacitors operate between rated voltage and one-half rated voltage, and the power in and out of the capacitors is controlled by interface electronics to maintain a near-constant battery power (See figures 1 and 2 ). Capacitors are capable of providing short power pulses at very high power density ( 2 to $3 \mathrm{~W} / \mathrm{kg}$ ), but the simulation results indicate that for elertric vehicle applications, operation at power densities above $500 \mathrm{~W} / \mathrm{kg}$ is not 


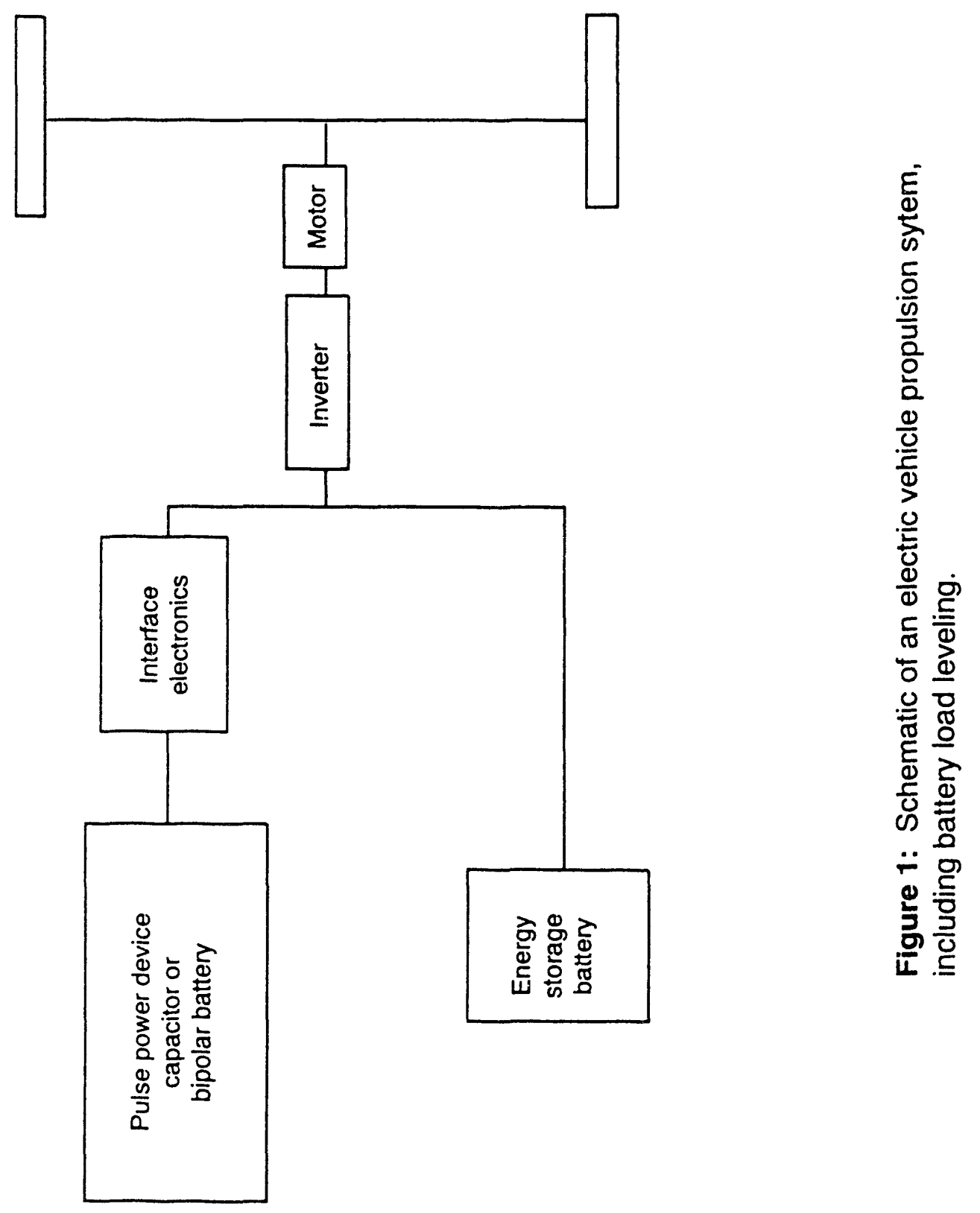


Cycle 2 DSEP TB-1 ON FUDS

$1372 \mathrm{sec} \quad$ Battery: 15 6ET-105 Module(s)
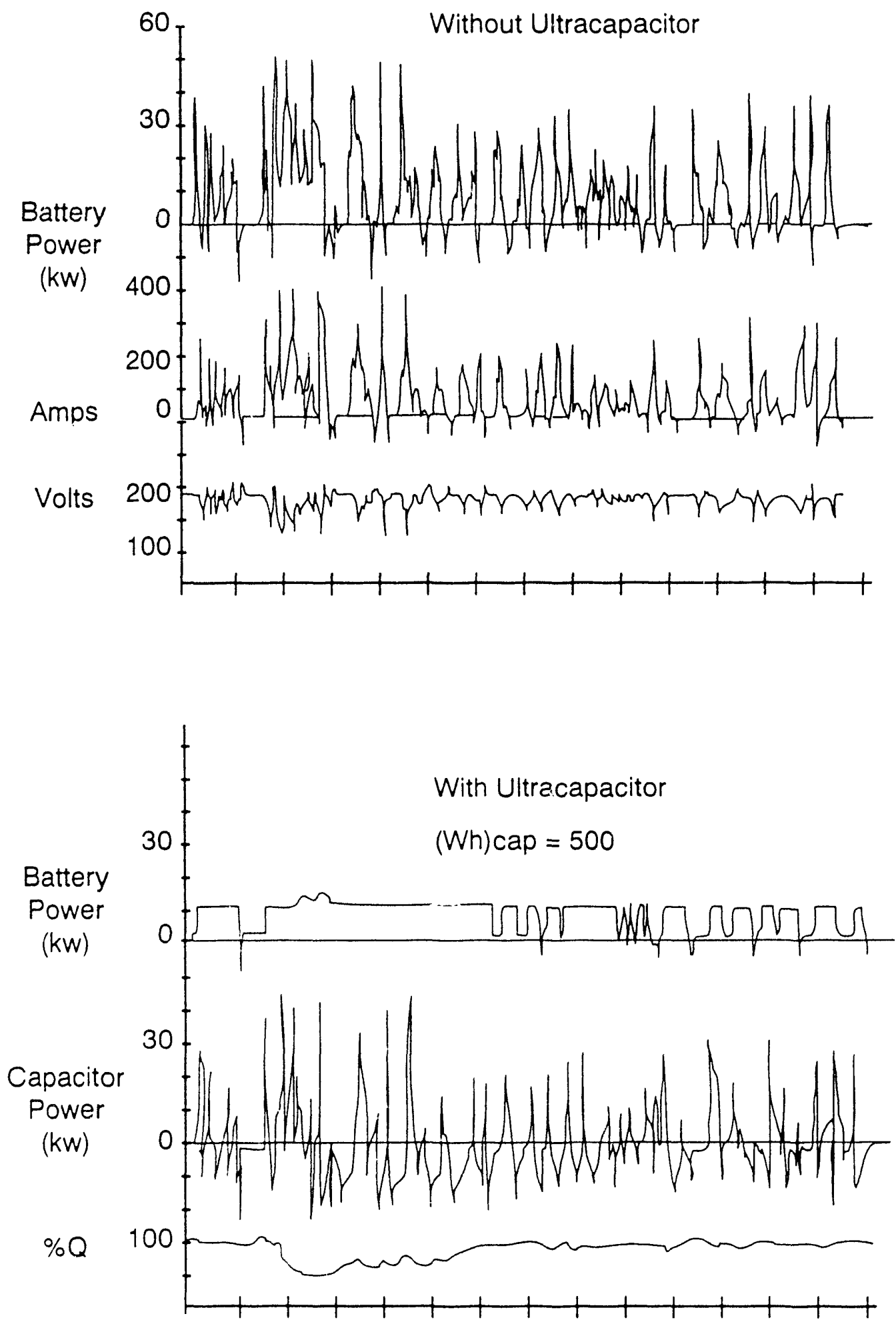

Figure 2: The effect of the ultracapacitor on the battery power profile on the FUDS cycle. 
Table 1. Capacitor specification for electric vehicle applications

\begin{tabular}{|c|c|}
\hline Energy storage * $(W h, M J)$ & $500,1.8$ \\
\hline Power (kW) & 50 \\
\hline Voltage (V) & $200-300$ \\
\hline Weight $(\mathrm{kg})$ & $<100$ \\
\hline Volume $(\ell)$ & $<45$ \\
\hline Specific energy $*(\mathrm{Wh} / \mathrm{kg})$ & $>5$ \\
\hline Vol. specific energy $*(W h / \ell)$ & $>11$ \\
\hline Capacitance ( $\mathrm{F} / \mathrm{cm}^{2}$ lvcell) & $>1.5$ \\
\hline Resistance (m-ohm $\mathrm{cm}^{2} / 1$ vce 11$)$ & $<100$ \\
\hline Discharge time (sec) & $20-50$ \\
\hline Charge time (sec) & $60-120$ \\
\hline Duty cycle & continuous \\
\hline Cycle life & $>100,000$ \\
\hline $\operatorname{cost}(\$)$ & $<1,000$ \\
\hline$\star 1 \frac{\mathrm{Wh}}{\mathrm{kg}}=3.6 \frac{\mathrm{kJ}}{\mathrm{kg}}$ & \\
\hline $1 \frac{\mathrm{Wh}}{\ell}=3.6 \frac{\mathrm{kJ}}{\ell}$ & \\
\hline
\end{tabular}


required. These devices are representative of the state-of-the-art of the carbon-based and mixed oxide (Ruthenium)-based technologies. Their construction is very different, with the Pinnacle devices being bipolar in configuration and the Japanese devices being spiral wound. For high voltage applications such as electric vehicles, the bipolar design is preferred, because of the ease of packaging long series strings of the devices. The energy density of the Japanese device is about twice that of the Pinnacle device with both devices having an energy density significantly less than the specification of $5 \mathrm{Wh} / \mathrm{kg}$ and $11 \mathrm{Wh} / 1$. The power capability of the bipolar Pinnacle device is higher than that of the spiral wound Japanese device indicating there are energy-power trade-offs in capacitor design as there are in battery design. The difference in the power capability of the two devices will be discussed later in the report.

High energy density capacitor technology is improving rapidly at the present time, so that there are undoubtedly higher energy density devices than those tested in this program under development in laboratories around the world. 


\section{CAPACITOR DEVICES}

Two types (see Figures 3 and 4 for photographs of the devices) of high energy density c:pacitors were procured for evaluation and testing. One type (two devices) was made by a Japanese company. The second type (ten devices) was specially fabricated for this program by Pinnacle Research Institute, Cupertino, California. The characteristics of each type of device are given below.

\section{Japanese $3.5 \vee$ Capacitor}

$\begin{array}{ll}\text { Technology } & \begin{array}{l}\text { single cell, spiral wound, carbon-based, } \\ \text { non-aqueous electrolyte }\end{array} \\ \text { Rating (max.) } & 3.5 \mathrm{~V}, 70 \text { Farads } \\ \text { Energy Stored } & 430 \mathrm{~W} \mathrm{sec} \\ \text { Size } & \begin{array}{l}\text { Diameter } 3.3 \mathrm{~cm} \\ \text { Length } 5.0 \mathrm{~cm}\end{array} \\ & \text { Volume } 42.7 \mathrm{~cm} 3 \text { (excl. terminals) } \\ \text { Weight } & 66 \mathrm{gm}+\text { or }-.5 \mathrm{gm} \\ \text { Energy density } & 1.8 \mathrm{Wh} / \mathrm{kg}(6.48 \mathrm{~J} / \mathrm{gm}) \\ & 2.8 \mathrm{Wh} / 1(10.1 \mathrm{~kJ} / 1)\end{array}$

\section{Pinnacle $20 \mathrm{~V}$ Capacitor}

Technology

20 cells, bipolar construction, mixed oxide-based, sulfuric acid

Rating (max.)

$20 \mathrm{~V}, 3.0$ Farads

Energy Stored

$600 \mathrm{~W} \mathrm{sec}$

Size

Diameter $8.4 \mathrm{~cm}$

Height $1.2 \mathrm{~cm}$

Weight

Volume

$67 \mathrm{~cm} 3$

Energy Density (nominal)

$210 \mathrm{gm}$

$0.8 \mathrm{Wh} / \mathrm{kg}(2.9 \mathrm{~J} / \mathrm{gm})$

$2.5 \mathrm{Wh} / \mathrm{l}(9.0 \mathrm{~kJ} / 1)$ 


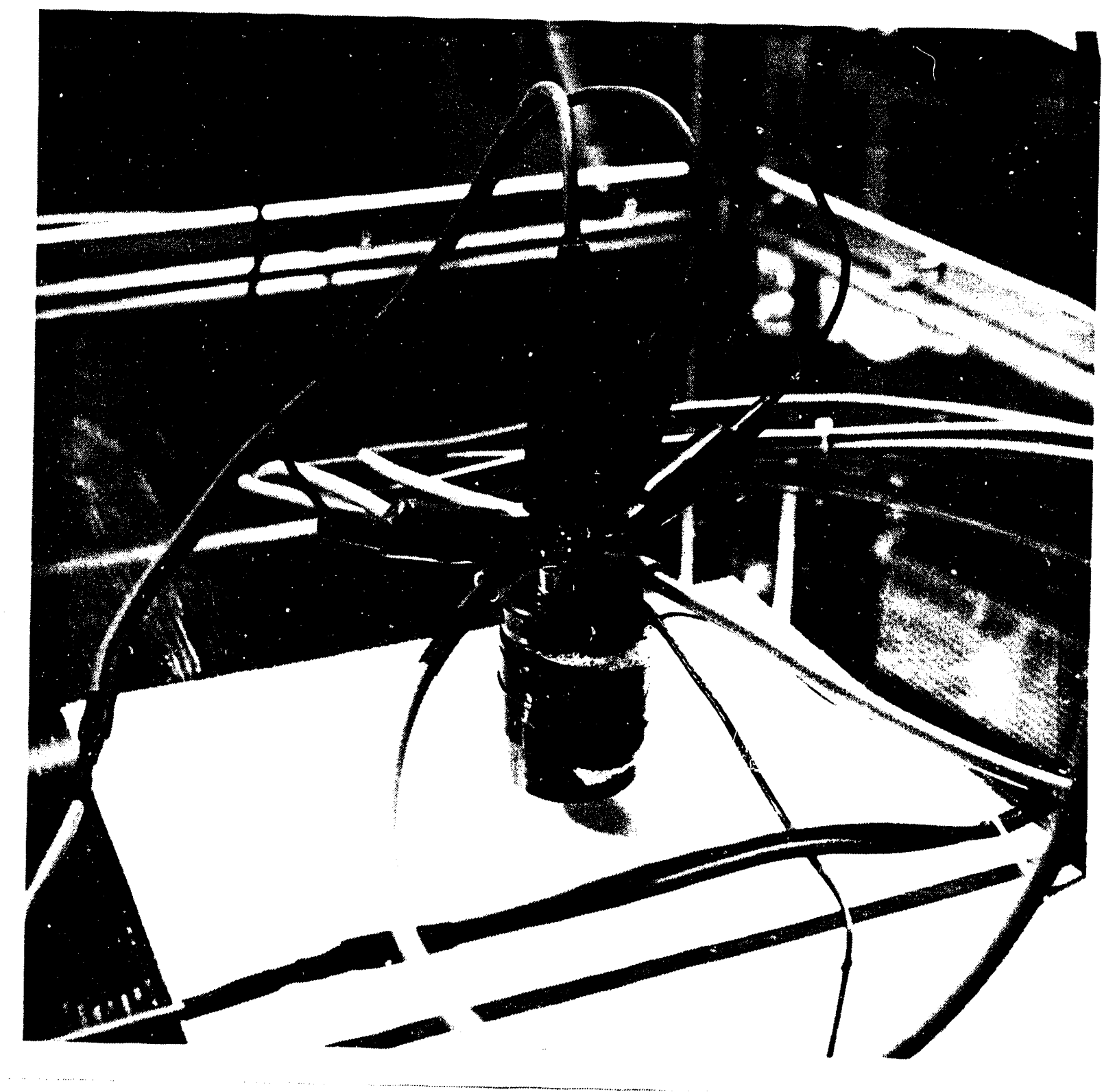

Figure 3. The Japanese Capacitor in the test set-up. 


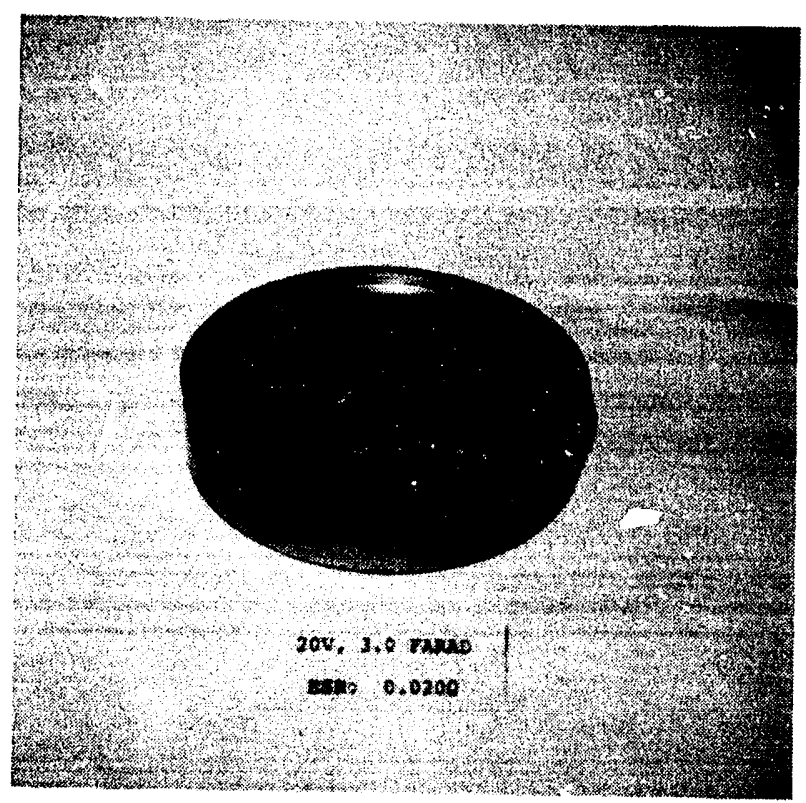

Figure 4: Photograph of a Pinnacle Research Ultracapcitor (3" dia.). 


\section{TEST EQUIPMENT AND PROCEDURES}

In the present work, the equipment in the INEL Battery Test Laboratory was utilized for the evaluation of high energy density capacitors. Procedures and test cycles were developed for testing such devices for electric vehicle applications. Capacitors used to load level the battery in an electric vehicle are charged and discharged many times during a single charge/discharge cycle of the main storage battery. Hence both the charge and discharge rates of the capacitors are much higher than for the main traction batteries. In addition, the energy storage capacities of the capacitor devices are small compared to battery cells. The capacitor devices tested had energy capacities of $120 \mathrm{mWh}$ and $166 \mathrm{mWh}$ compared with 200-300 Wh/cell for typical batteries for electric vehicles. The corresponding amp-hour capacities of the capacitors and batteries are $68 \mathrm{mAh}, 16 \mathrm{mAh}$, and 100-150 Ah, respectively. The small capacity of the capacitor devices means that the discharge and charge currents used in their tests are much smaller than used in battery tests and that the durations of the capacitor test cycles are seconds rather than hours as is the case for batteries. The life of a capacitor device is given in hundreds of thousands of charge/discharge cycles rather than hundreds of cycles as is common for batteries. As will be discussed in subsequent sections, these differences between batteries and capacitors require changes in how the equipment in the battery test laboratory is used and the test cycles utilized to evaluate the devices.

Four types of tests were performed on the capacitor devices. These were:

1. Characterization tests to determine the coulomb and energy capacity of the devices at different charge and discharge rates.

2. Cycle tests to determine the behavior of the devices to repeated, variable power charge and discharges over long time periods (hours).

3. Life cycle tests to determine whether the devices can perform repeated charge/discharge cycles over very long periods of time (days or months) with a minimal degradation of capacity. 
4. Thermal response tests to determine how the losses during repeated, charge/ discharge cycles affect the temperature of the devices.

The test equipment and the procedures used in each of these tests is discussed in the following sections.

\section{TEST EOUIPMENT}

\section{Battery Test Cycler}

The capacitor characterization and cycle tests were performed using a Bitrode battery test cycler. This unit is customarily used to test battery cells and modules at voltages up to $20 \mathrm{~V}$. The Bitrode tester is a PC-based, stand-alone unit (see Figure 5) which can be programmed for user specified charge and discharge profiles. Constant current, constant power, and variable power profiles are easily implemented. The user can also specify maximum voltages for charge and minimum voltages for discharge. All of these features of the Bitrode tester were utilized in the present tests of the capacitor devices. The Bitrode tester has Pc-based data acquisition capability with sampling rates up to 10 scans per second. It can also be interfaced with a stand-alone Neff PC-based data acquisition unit, as was done for most of the capacitor tests, to achieve maximum flexibility in data measurement accuracy, acquisition, playback, and reduction.

For battery testing, the maximum current limits for the Bitrode are $500 \mathrm{~A}$ in discharge and $150 \mathrm{~A}$ in charge with an accuracy of $1 \%$ and a maximum sensitivity of $1 \mathrm{~A}$ or 10 Watts. In normal use, the tester utilizes a $500 \mathrm{~A}$, $100 \mathrm{mV}$ shunt. For the capacitor tests, a $50 \mathrm{~A}, 100 \mathrm{mV}$ shunt was used to increase the sensitivity of the Bitrode tester to $100 \mathrm{~mA}$ and 1 Watt. The voltage requirements for the tests of the capacitor devices are the same as for the usual battery tests, so voltage measurement presented no difficulty. The Bitrode tester was programmed for the various capacitor tests in the same manner as for battery tests. In the case of variable power tests, the power profile was specified as a function of time in one second increments. The 


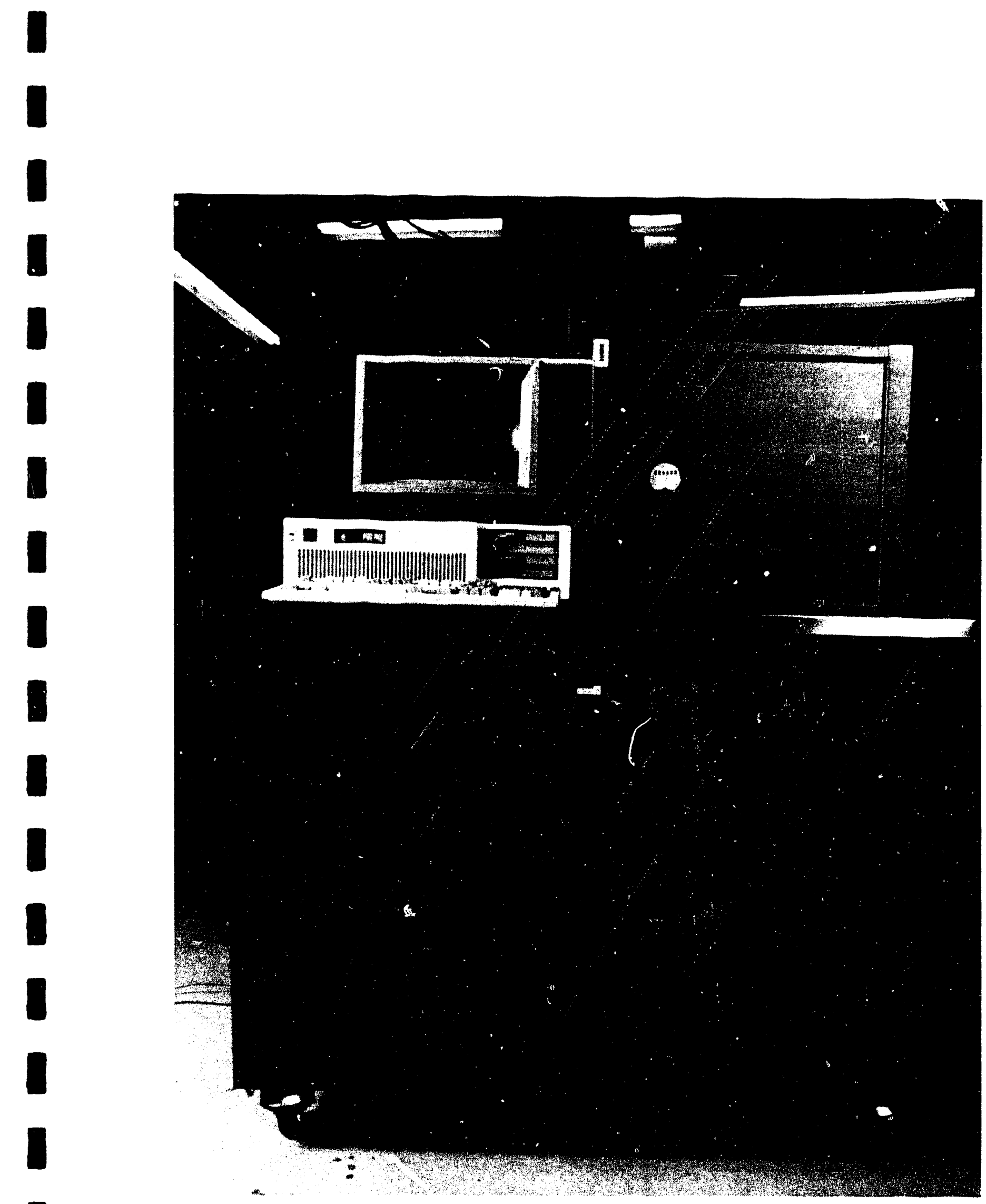

Figure 5: Bitrode Test Equipment. 
power command is updated at one second intervals by the tester controller, so that the minimum test/cycle time that could be used was several seconds. Otherwise, the Bitrode would not follow the specified power profile and maintain the voltage limits during charge/discharge portions of the tests. During a test, data could be taken at time intervals as short as $100 \mathrm{~ms}$ to track the response of the devices during high power discharges and sudden changes between charge and discharge modes. The Bitrode functioned well during the capacitor tests with the one second control interval being the only linitation encountered.

\section{Environmental Chamber and Thermal Test Set-Up}

The thermal response tests were conducted using the test enclosure shown schematically in Figure 6 . The test apparatus was placed inside an environmental chamber to maintain a near collstant ambient temperature. The environmental chamber can be used to provide a controlled temperature of -20 to $80^{\circ} \mathrm{C}$ to within $1^{\circ} \mathrm{C}$ for battery testing. The heat loss characteristics of the thermal enclosure, in which the capacitor devices were placed, were determined by tracking the decrease in the temperature of the hot water bath without the capacitor being energized. Calibration tests in the open laboratory disclosed a need for performing the thermal tests in the environmental chamber which permitted the thermal tests to be performed with the minimum of difficulty.

\section{Life Cycle Test Set-Up}

Long-term life cycle tests of the capacitor devices were performed using the test set-up shown in Figure 7. The test cycle used consisted of a constant current charge followed by a constant current discharge, with the complete cycle being about 30 seconds. The charge portion of the cycle was terminated at a specified maximum voltage and the discharge portion was terminated at a specified minimum voltage. Switching between charge and discharge was done electronically using a FETS device made to change conduction modes at the specified voltages. The cycle was repeated continuously without interruption for days/weeks. The operation of the 

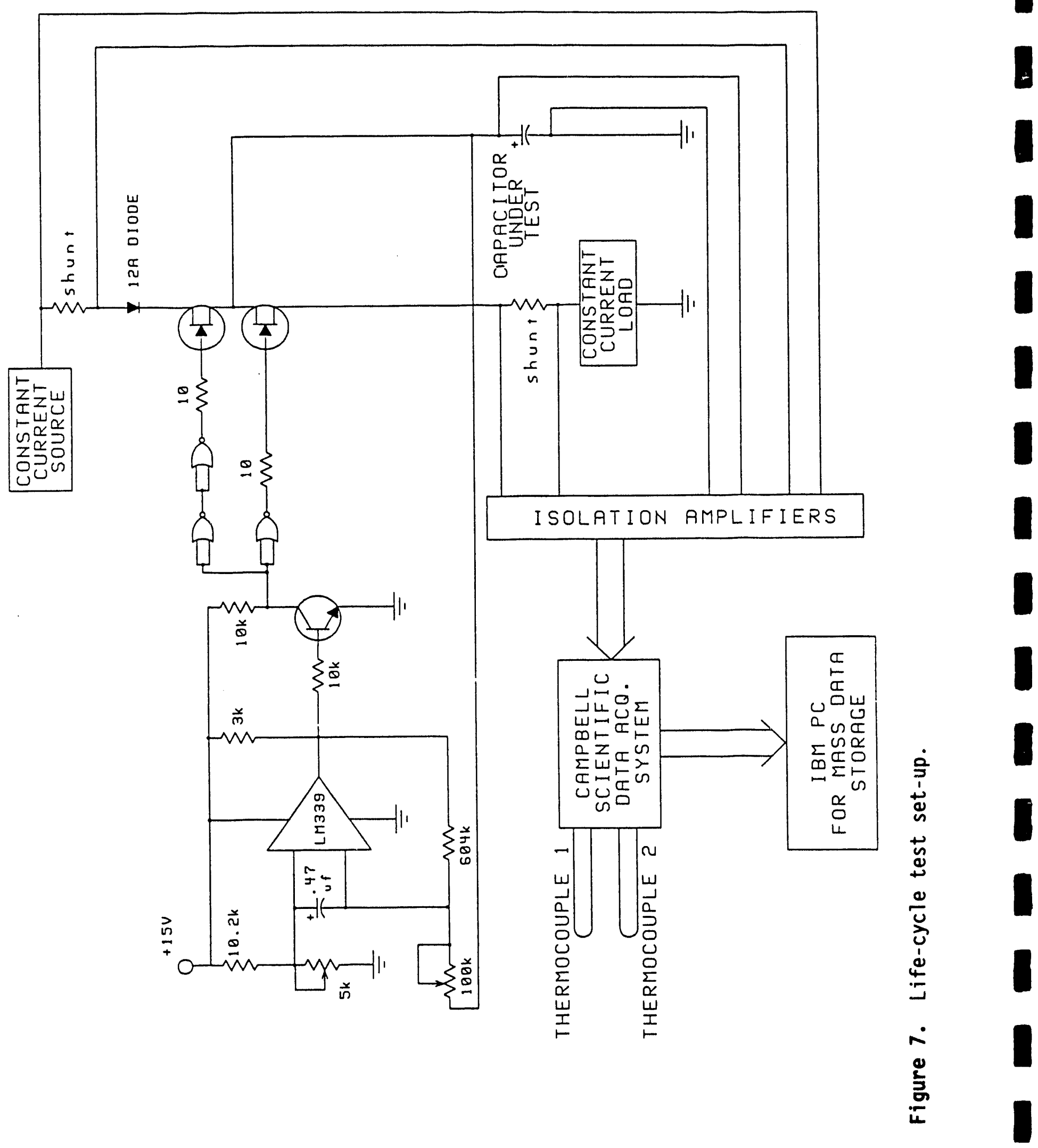
capacitor was monitored by a PC using specially prepared software that would shut-down the test if any of the currents, voltages, or temperatures deviated from set ranges. Test data was acquired by the PC and stored on its hard-disk at user specified intervals. In addition, the software would automatically store data from a cycle in which the test was terminated by the monitoring program. The performance of the capacitor device was checked several times a day by displaying the voltage versus time trace for several cycles on a strip-chart recorder and noting the time for the cilarge and discharge portions of the cycle. After the test set-up was debugged, the life cycle test of the Japanese capacitor ran for weeks without interruption.

\section{Test Proredures}

\section{Device Characterization Tests}

The purposes of the characterization tests wer, determine the coulomb (charge) and energy capacity of the capacitor devices at various charge and discharge rates and to relate the behavior of the devices to that of an ideal capacitor, which can be described in terms of the following simple relations:

$$
\begin{aligned}
& Q=C * V \\
& E=1 / 2 \quad C * V 2
\end{aligned}
$$

where

$Q$ is the charge and $E$ is the energy on the capacitor at Voltage (V) and $C$ is the capacitance of the capacitor. The characterization tests consisted of discharges through fixed resistors and at constant currents and powers. A series of test conditions were selected such that the average power density for the discharges varied between 25 and $1500 \mathrm{~W} / \mathrm{kg}$. Each of the discharge tests is initiated from the same voltage vo after a charge at a specified constant current. The discharge was terminated at a specified voltage, which was usually near $0.5 \mathrm{~V}$. For an ideal capacitor, the voltage versus time relationships for discharge through a fixed resistor (R), at constant power 
(P), and constant current (I) are given by

$V / V 0=e-(t / R * C)$
$V 2-(V 0) 2=-2(P / C) \star t$
$V-V 0=-(I / C) \star t$

where

vo is the initial voltage.

The coulomb and energy capacities at the different charge and discharge rates $(W / \mathrm{kg})$ are calculated from the test data by integrating the current and power over the time. The results are then plotted as a function of average power density for the test. An ideal capacitor would show little or no dependency of capacity (or effective capacitance) on discharge rate. The effective dc resistance of the capacitor can be determined from the discontinuous jump in voltage at the outset of charging or at the initiation of a constant current discharge after charging is complete. The dc resistance can be higher than the ac resistance measured at $1 \mathrm{kHz}$ with an ac impedance bridge. An ideal capacitor would exhibit a very small resistance and little or no discontinuity in voltage as the device is switched between charge and discharge.

\section{PSFUDS (variable power) Tests}

These tests are intended to determine the behavior of the capacitor on a test cycle simulating the use of the device to load level the main battery in an electric vehicle. Hence the cycle has been named the "PSFUDS" for pulsed SFUDS. The required charicteristics of the PSFUDS were determined using the SIMPLEV simulation program (Reference 3 ). The cycle used in the present study does not meet these requirements in detail, because the energy capacity of available capacitors is not sufficiently large to permit the high power steps $(300 \mathrm{~W} / \mathrm{kg})$ in the PSFUDS to be sustained long enough to meet the peak and/or average discharge power required by the SIMPLEV results. The PSFUDS cycle used in the present study is given in Table 2 as a series of power steps ( $W / \mathrm{kg}$ for a specified number of seconds). In future studies with higher energy 
Table 2. Power profile for the PSFUDS test cycle used in the present study.

\begin{tabular}{|c|c|c|}
\hline Time Step (sec) & $\mathrm{W} / \mathbf{k g}$ & Mode \\
\hline 3 & 100 & Discharge \\
\hline 5 & 200 & Discharge \\
\hline 5 & 50 & Discharge \\
\hline 20 & 50 & Charge \\
\hline 5 & 100 & Discharge \\
\hline 5 & 300 & Discharge \\
\hline 3 & 200 & Discharge \\
\hline 20 & 100 & Charge \\
\hline 5 & 100 & Discharge \\
\hline 5 & 200 & Discharge \\
\hline 7 & 50 & Discharge \\
\hline 20 & 100 & Charge \\
\hline 3 & 100 & Discharge \\
\hline 5 & 300 & Discharge \\
\hline 5 & 50 & Discharge \\
\hline 20 & 125 & Charge \\
\hline 3 & 100 & Discharge \\
\hline 5 & 300 & Discharge \\
\hline 15 & 100 & Charge \\
\hline 5 & 200 & Discharge \\
\hline 5 & 100 & Discharge \\
\hline$>20$ & 125 & Charge (to Vo) \\
\hline $189 \mathrm{sec}$ & & \\
\hline
\end{tabular}


density devices, the peak power steps will be increased to $500 \mathrm{~W} / \mathrm{kg}$. The device weight is used to convert the $W / \mathrm{kg}$ value of each step to a power in Watts. The duration of the PSFUDS cycle in Table 2 is 190 seconds, representing six charge/discharge subcycles of the capacitor. After the final subcycle, the device is charged to the initial voltage VO and the complete PSFUDS cycle is repeated up to 100 times. In principle, each of the PSFUDS cycles should be the same as the capacitor starts each cycle from the same voltage. Typical plots of current and voltage versus time for the Japanese capacitor on the PSFUDS cycle are shown in Figure 8.

\section{Life Cycle Tests}

The life cycle tests of the capacitors are intended to simulate long-term use of the devices to load level the main battery in an electric vehicle. This requires at least 100,000 charge/discharge cycles over the life of the device. As discussed earlier in the report, the test cycle used for these tests is a simple constant current charge followed by a constant current discharge. A time of 30 seconds for the complete cycle was selected to match closely to the average charge/discharge time in the PSFUDS cycle. The voltage limits between which the capacitor is charged and discharged are the same as used in the PSFUDS tests. The constant current used to charge and discharge the device in 30 seconds can be determined from the characterization test results. Once the life cycle test is set up, it runs continuously for weeks unless it is automatically shutdown by the computer due to a malfunction of the test equipment or the device being tested. The testing is then restarted after the malfunction in the equipment has been corrected. The voltage-time record for the cycle is checked periodically to determine if the charge/discharge cycle time has decreased from the initial value. A decrease in the cycle time would indicate the capacitance of the device being tested has degraded. In addition, an increase in the voltage jumps at the beginning and end of the charge/discharge portions of the cycle indicates an increase in the dc resistance of the device. The life cycle test is terminated when the cycle time has decreased by about $20 \%$, indicating a degradation of $20 \%$ in the capacitance of the device. A counter that is triggered by the initiation of the charge for each cycle records the total number of cycles for the test. 


\section{Capacitor \#1, 1st Cycle PSFUDS}



- Current (Amps)

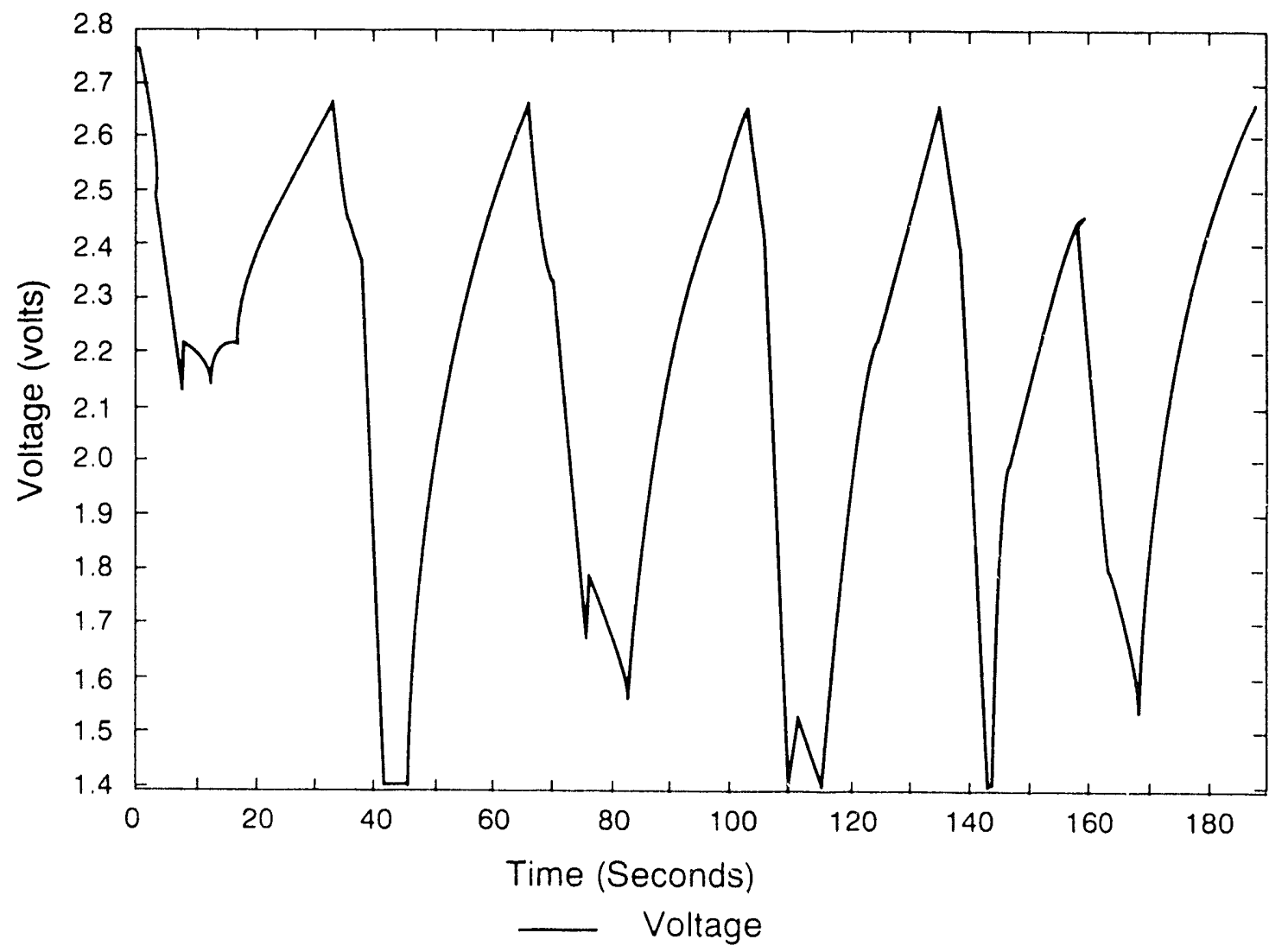

Figure 8: Current and voltage traces for the Japanese capacitor on the PSFUDS cycle. 


\section{Thermal Response Tests}

In the thermal response tests, the capacitor device is tested using the PSFUDS cycle with the device in a thermally insulated water bath (see Figure $6)$. The test is done with the test apparatus placed in the environmental chamber. Thermocouples are attached to the capacitor device and inserted into the water bath and the air above the bath. The temperatures are recorded by the Neff PC-based stand-alone data acquisition system using a 10-point software filter to smooth the data. During a thermal response test, the capacitor is subjected to 100-150 PSFUDS cycles in 5-7 hours. Data are taken with the PC about every 10 PSFUDS cycles. Temperature data can also be read manually from a digital thermocouple meter at intermediate times if desired. Temperatures change slowly during the test. Each PSFUDS cycle is nearly isothermal, but over the course of the complete 5-7 hour test, the water bath temperature increases $4-6^{\circ} \mathrm{C}$. The magnitude of the heat generated by the cycling of the capacitor is determined from the rate at which the water bath temperature increases correcting for the heat lost from the bath to the constant temperature environment of the chamber. The heat generated for a particular PSFUDS cycle can also be determined from the electrical data by comparing the energies from the charge and discharge portions of the cycle. The difference between the charge and discharge energies is the heat generated during the cycle. As will be discussed later in the report, the thermal and electrical approaches to determining the charge/discharge cycle efficiency of the capacitors yield results in good agreement. 


\section{TEST RESULTS}

\section{The Japanese Capacitor}

\section{Performance Characteristics}

Tests of the Japanese capacitors were performed at various charge and discharge rates. A photograph of the capacitor test setup is shown in Figure 9. The maximum voltage in all the tests was $3.0 \mathrm{~V}$. The minimum voltage in discharge was $1.0 \mathrm{~V}$. The results of the charging tests are given in Figure 10 as a plot of charge $Q$ vs. $V$. An ideal capacitor would exhibit a linear relationship between $Q$ and $V$ with the slope being equal to the capacitance $C$. Figure 10 indicates that the magnitude of the non-ideal behavior in charging increases as the charging current is increased. The effective capacitance of the devices varied between 80 and 90 Farads and thus exceeded the 70 Farads $\mathrm{claimed}$ by the manufacturer even for charging times as short as 20 seconds. It seems reasonable to rate high energy density capacitors based on the effective capacitance Ceff(=2Eo/Vo2) calculated from the energy Eo stored in charge as it varies only slightly with the rate of charge. This is not the case for the energy extracted when the capacitor is discharged.

The Japanese capacitors were discharged at constant power between 5 and $64 \mathrm{~W}$. The corresponding power densities $(\mathrm{W} / \mathrm{kg})$ are 75 and 1000 . The results are given in Figures 11 and 12 . The $Q$ versus $V$ plots in Figure 11 show a linear relationship over much of the voltage range of interest as would be the case for an ideal capacitor, but the slope is rate dependent. The effective capacitance varies from 80 Farads at $75-150 \mathrm{~W} / \mathrm{kg}$ to 26 Farads at about 1000 $\mathrm{W} / \mathrm{kg}$. The discharge times vary from about 40 seconds for a $5 \mathrm{~W}$ discharge to less than a second for the $64 \mathrm{~W}$ discharge. As shown in Figure 12, the charge and energy that can be extracted from the capacitor decreases rapidly as the rate of discharge is increased. Based on the results given in Figure 12, it was decided to 1 imit the discharge rate to $300 \mathrm{~W} / \mathrm{kg}$ (about $20 \mathrm{~W}$ per device) in the PSFUDS cycle testing that was performed after the characterization testing 


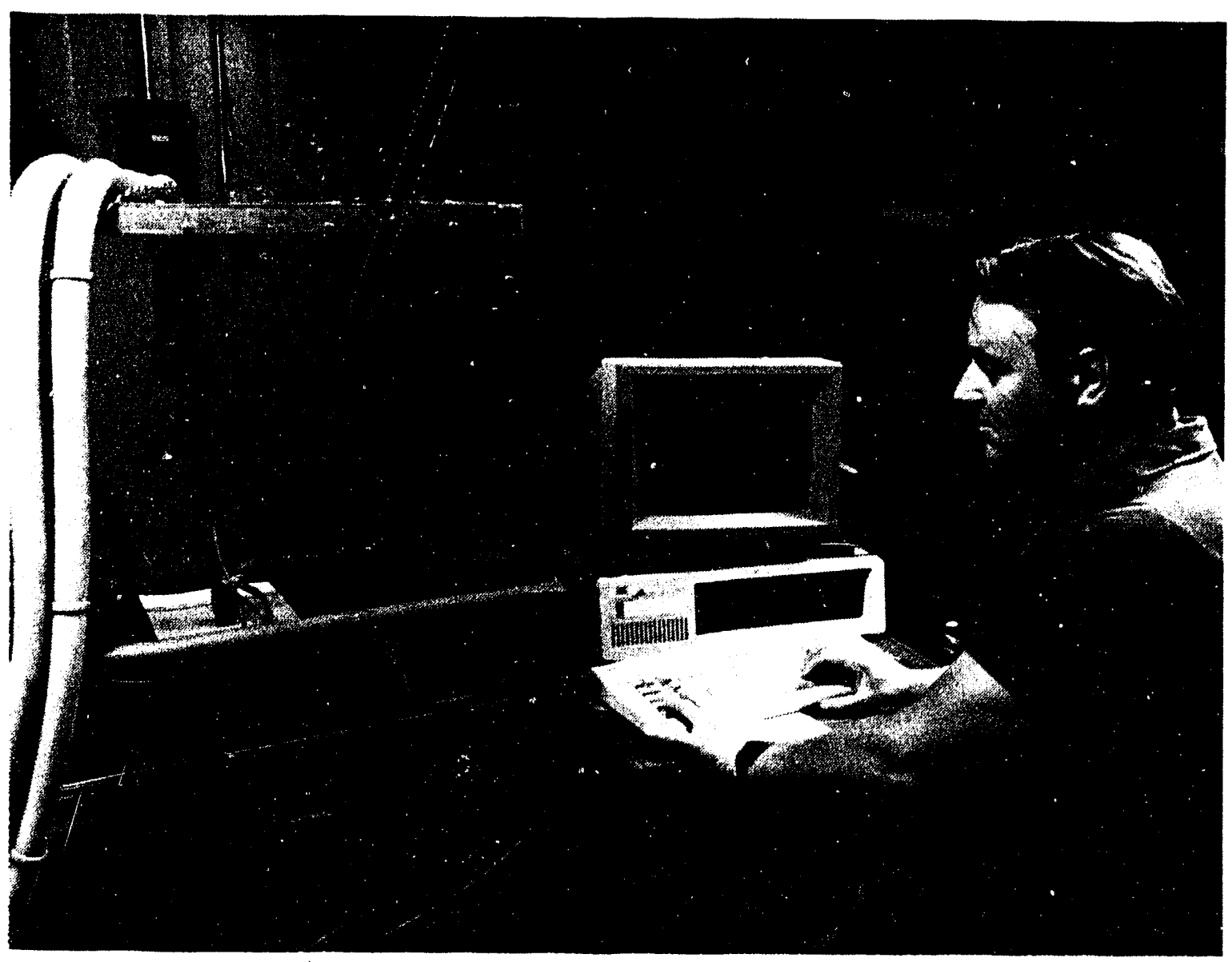

Figure 9: The capacitor test set-up with the data acquisition computer. 




Figure 10: Charging characteristic of the Japanese capacitor at several charging currents. 


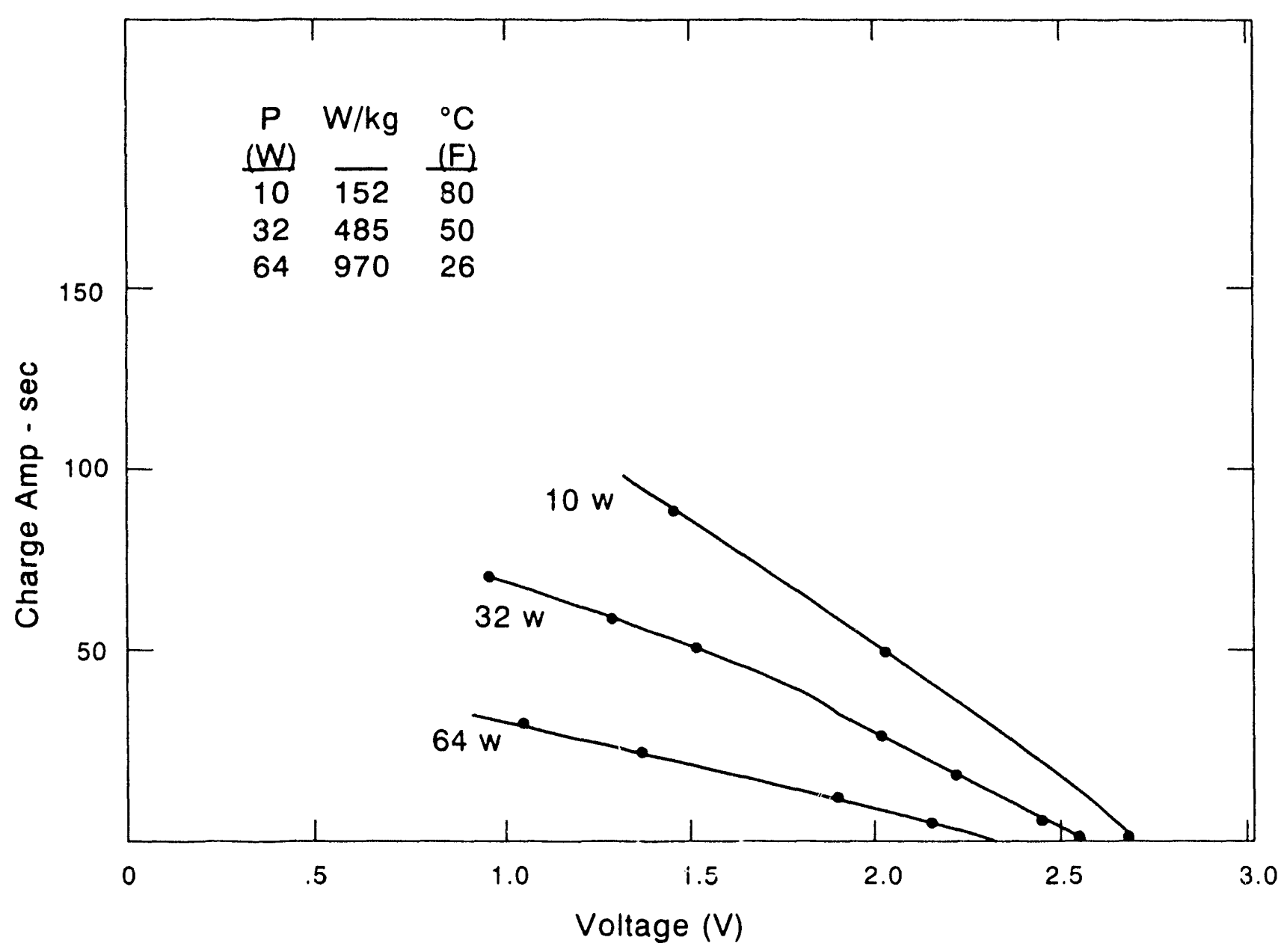

Figure 11: Discharge characteristics of the Japanese capacitor at various constant powers. 




Figure 12: Rate dependency of the energy and charge capacity of the Japanese capacitor for discharge at various constant power densities. 
was complete. Otherwise, the energy stored in the capacitor would be depleted too rapidly and the high power steps in the PSFUDS cycle would be too short for the Bitrode tester to control. In the electric vehicle application of high energy density capacitors, the peak power required from the devices will be below that at which the devices suffer a large decrease in capacitance.

The dc resistance of the capacitors can be determined from the characterization test data when the current is set equal to zero at the end of a charge or discharge. In either case there is a sudden change in the voltage, which is the IR voltage drop due to the dc resistance of the device. The data shown in Table 3 indicates that the dc resistance of the Japanese capacitor is about 29 milliohms. Measurements of the resistance of the devices with an ac impedance bridge (HP 4192 A) indicated a resistance of 28-29 milliohms at $1 \mathrm{kHz}$, which is essentially the same as the value determined from the characterization data. The impedance bridge resistance measurement was nearly independent of frequency down to $0.1 \mathrm{kHz}$, which is the low frequency limit of the instrument. Hence for the carbon-based capacitors, the difference between the $d c$ and ac resistance is small.

The decay of the capacitor voltage after a charge to $3 \mathrm{~V}$ was measured to assess the leakage current of the device after it is disconnected from the energy source. The result is shown in Figure 13. After a step voltage decrease, which is the IR drop due to the charging current, the voltage decays at a decreasing rate apprnaching a leakage current of $90 \mu \mathrm{A}$ after about 10 hours when the voltage is $2.0 \mathrm{~V}$. The voltage recovery after a discharge to $0.0 \mathrm{~V}$ is shown in Figure 14. After the sudden jump, which is the removal of the IR drop due to the discharge current, the voltage increases by about $0.2 \mathrm{~V}$ in 100-200 seconds. This recovery is due to a redistribution of charge in the capacitor.

\section{PSFUDS Cycle}

The capacitors were tested on the PSFUDS cycle given in Table 2 for up to 32 hours of continuous operation. The power profile used in the PSFUDS tests is shown in Figure 15. The devices functioned uneventfully for the 576 
Table 3. The dc resistance of the Japanese Capacitors calculated from constant current charge/discharge data

\begin{tabular}{|c|c|c|c|}
\hline Charging & & & \\
\hline$I(A)$ & $\Delta V *$ & \multicolumn{2}{|c|}{$\operatorname{Reff}(\Omega)$} \\
\hline 5 & .15 & \multicolumn{2}{|c|}{.030} \\
\hline 5 & .14 & \multicolumn{2}{|c|}{.028} \\
\hline 2.5 & .08 & \multicolumn{2}{|c|}{.032} \\
\hline 5 & .14 & \multicolumn{2}{|c|}{.028} \\
\hline 10 & .28 & \multicolumn{2}{|c|}{.028} \\
\hline \multicolumn{4}{|l|}{ Discharge } \\
\hline$I(A)$ & $P(H)$ & $\Delta \mathbf{V}^{\star}$ & Reff( $(\Omega)$ \\
\hline 6.1 & 5 & .16 & .026 \\
\hline 11.4 & 10 & .28 & .028 \\
\hline
\end{tabular}

* $\Delta V$ at $0.5 \mathrm{sec}$. after change in current 


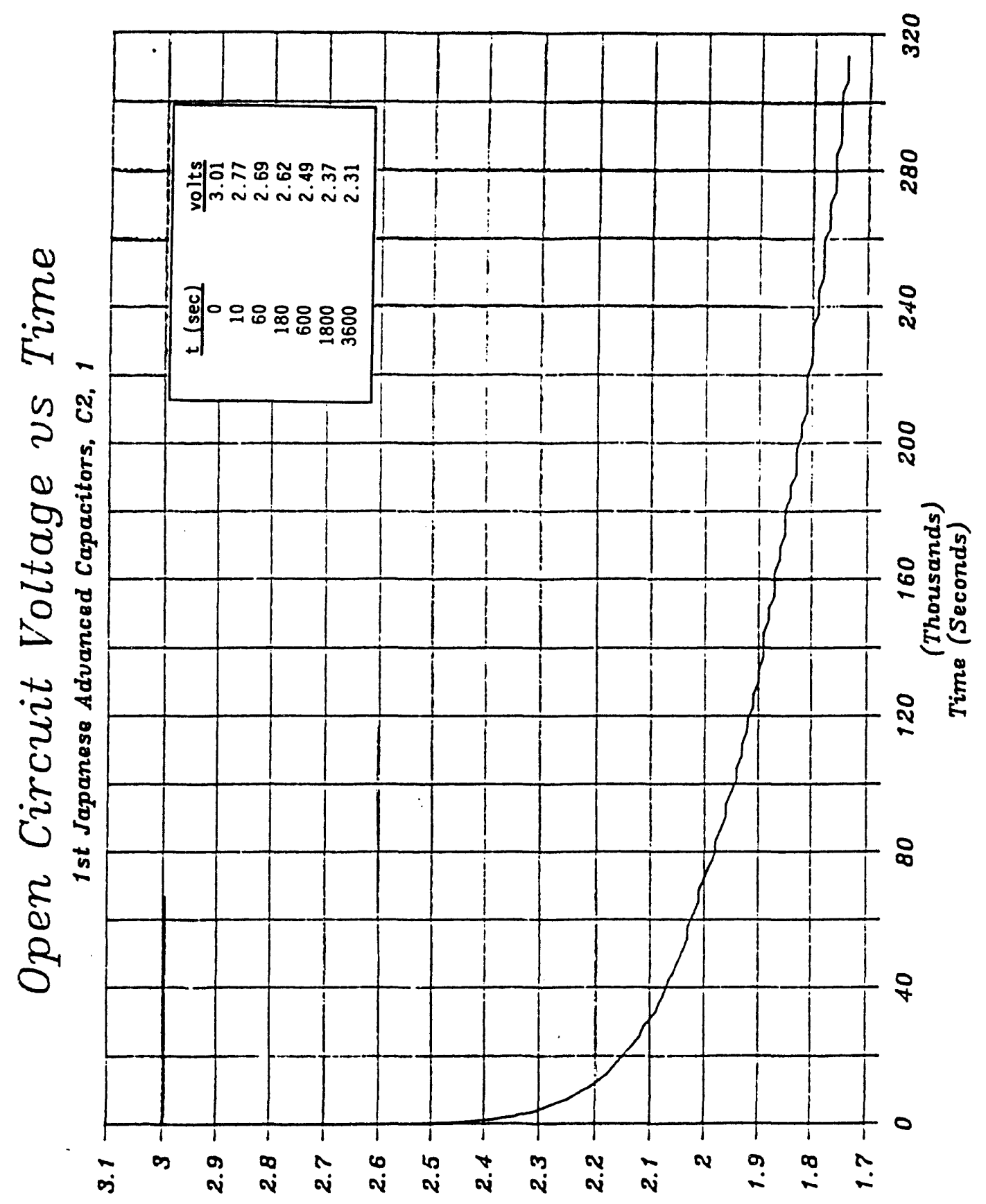

57201

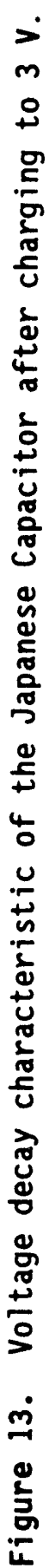




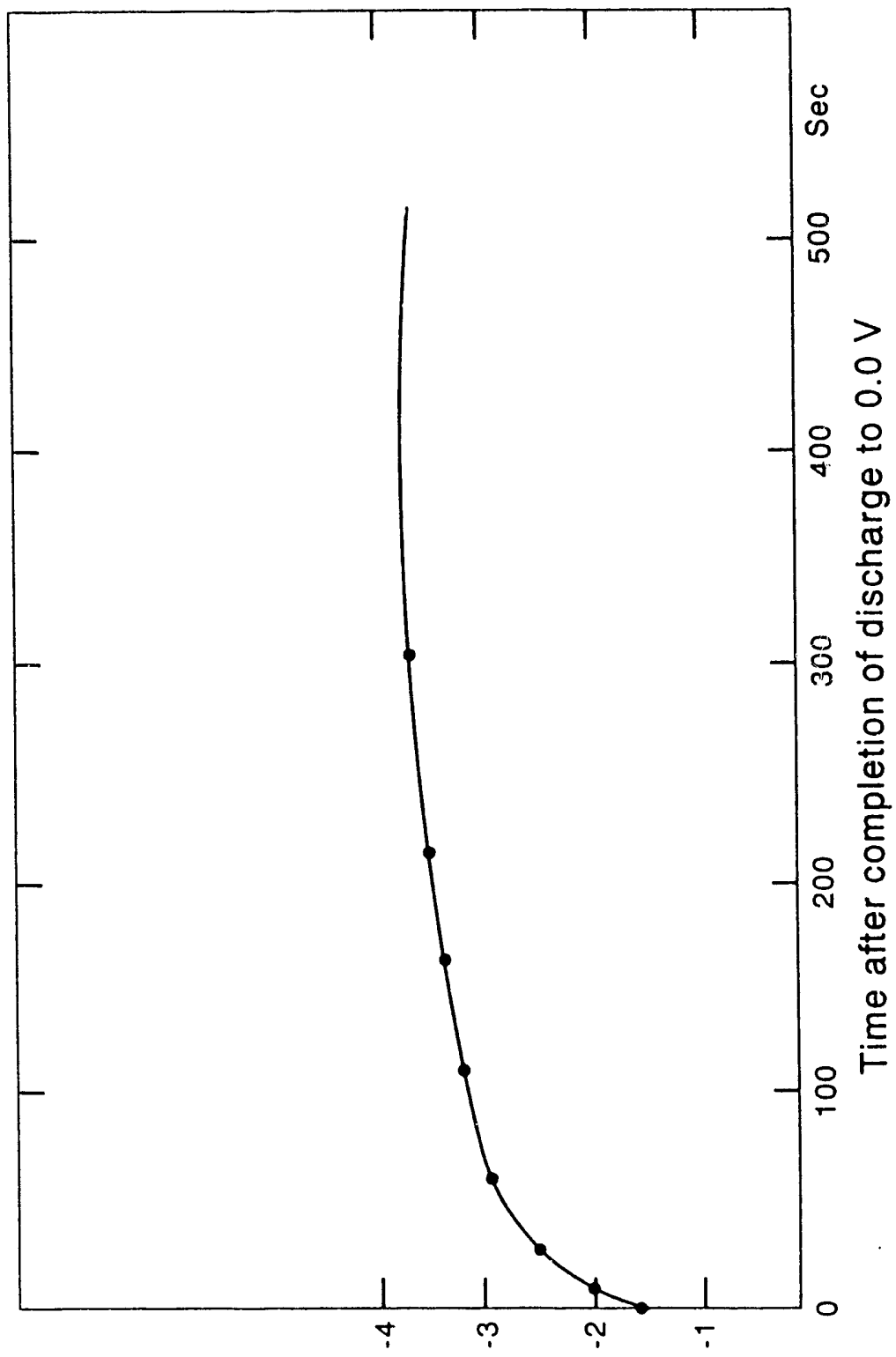

:

$+$

I

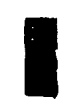

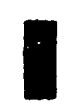

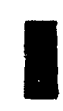

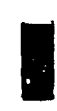

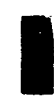

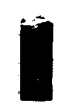

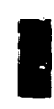

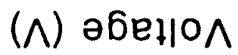




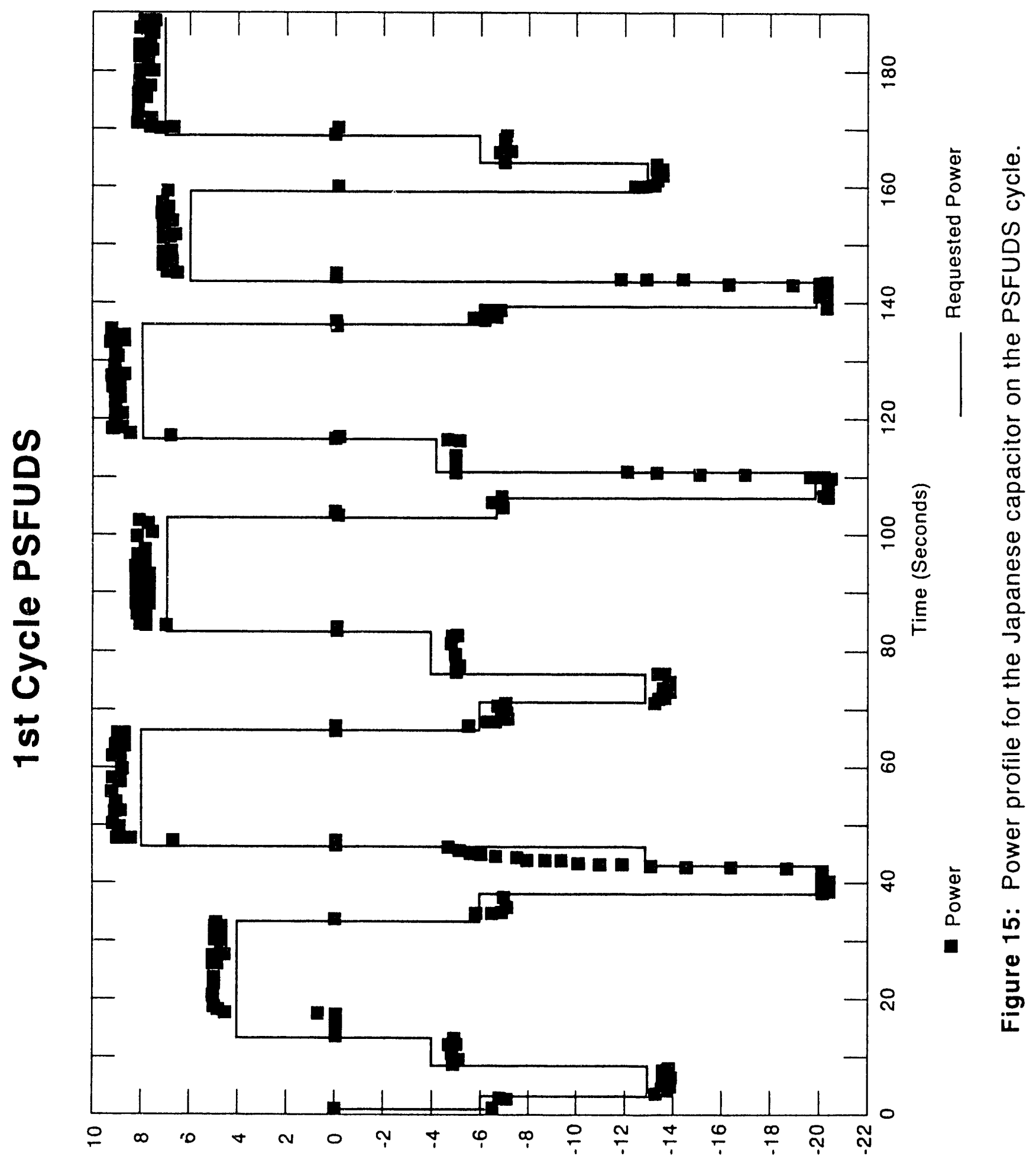

(shem) jamod 
cycles of the test, which included nearly 3500 charge/discharge periods for the device. Several shorter tests were run in which the two devices were connected in parallel. Those tests indicated the two devices were nearly identical as the current was shared nearly equally between the devices throughout the entire test.

In the PSFUDS tests, the capacitor was charged to $3 V$ at the end of each of the PSFUDS cycles, permitting the same cycle to be repeated. The final charge period was -25 seconds. This also allowed the electrical efficiency of the cycle to be calculated from the integrated energies in and out of the capacitor with the same voltage at the beginning and end of the cycle. The plots of voltage and current versus time are given in Figures 16-19 for a number of the 576 cycles of the test. Comparing the voltage and current curves for the various cycles shows that the capacitor functioned the same in early cycles (up to cycle 200) as in the late cycles (cycles 400-576). Analysis of the voltage and current data (Figures 16-19) indicated that the capacitors could be modeled with reasonable accuracy using the simple relation $Q=C V$ for the discharge rates $(W / k g<300)$ included in the PSFUDS cycle.

The temperature of the capacitor was measured during a long 32 hour test by attaching a thermocouple to the exterior of the device. The temperature varied between 22 and $29^{\circ} \mathrm{C}$. The maximum temperature seemed to track changes in room temperature. Since the heat loss to the environment was uncontrolled during the PSFUDS testing, it was not possible to utilize the temperature data to infer the magnitude of the heat generation (electrical losses) during the cycle. As discussed in an earlier section of the report, a thermal test procedure was then developed that permitted the efficiency of the cycle to be determined from the thermal response of the capacitor during cycling. The round-trip (charge/discharge) electrical efficiency of the capacitor on the PSFUDS cycle was found to be about $85 \%$ based on the integrated energies in and out of the device. The efficiency of the Japanese capacitor will be discussed in greater detail in a later section (Thermal Response Tests). 


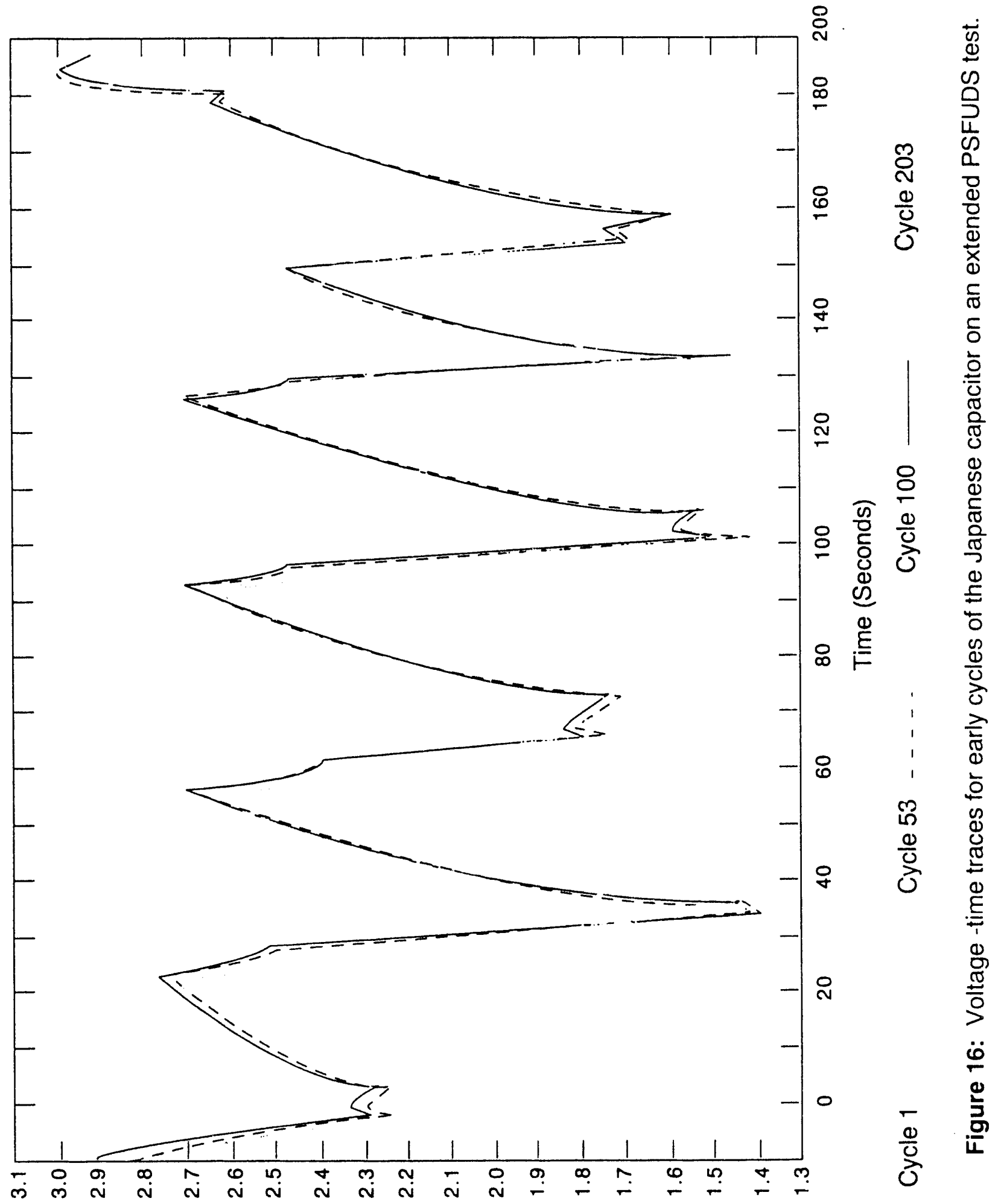

(shoN abejo^ 


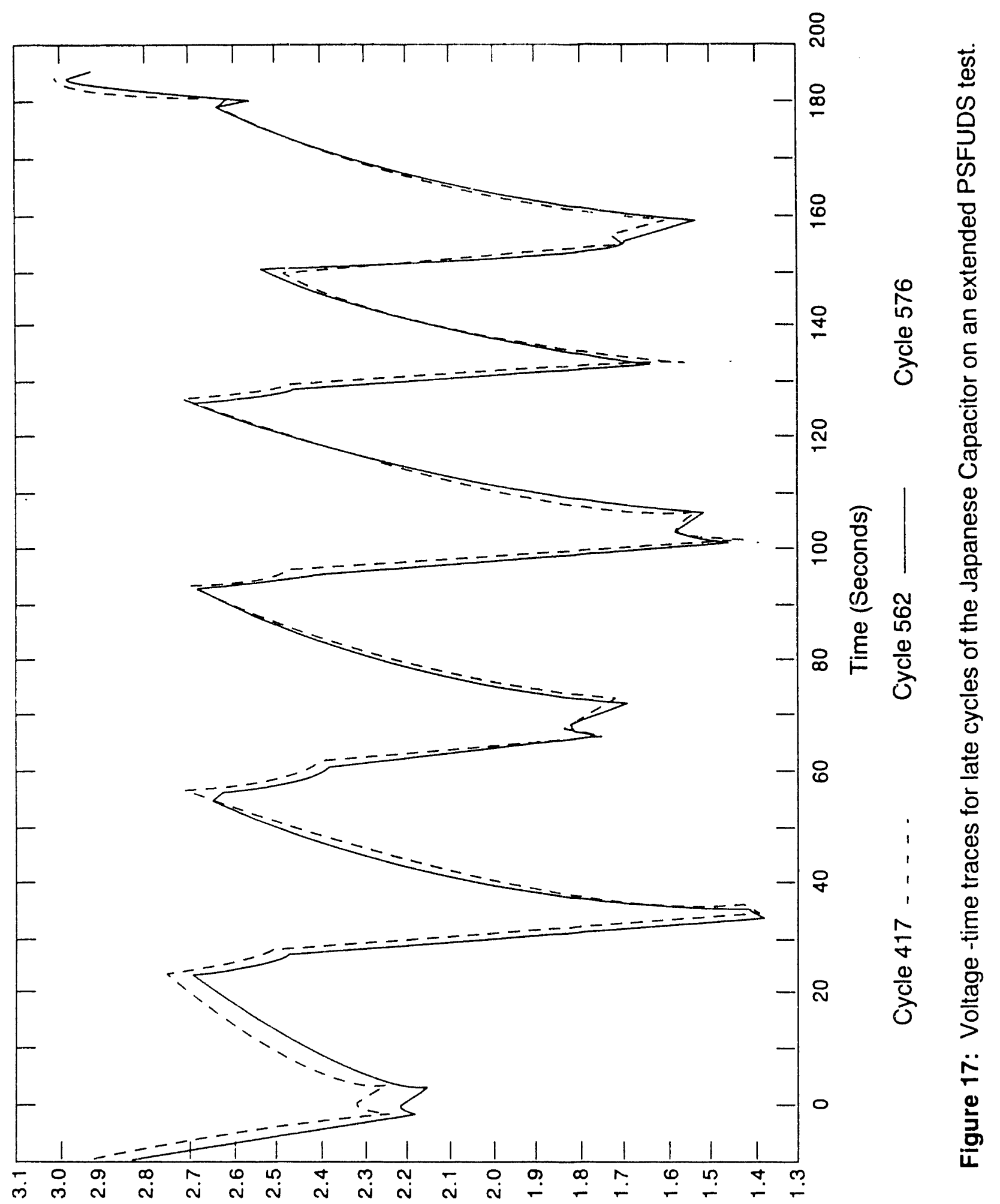

(shoN abeho^ 


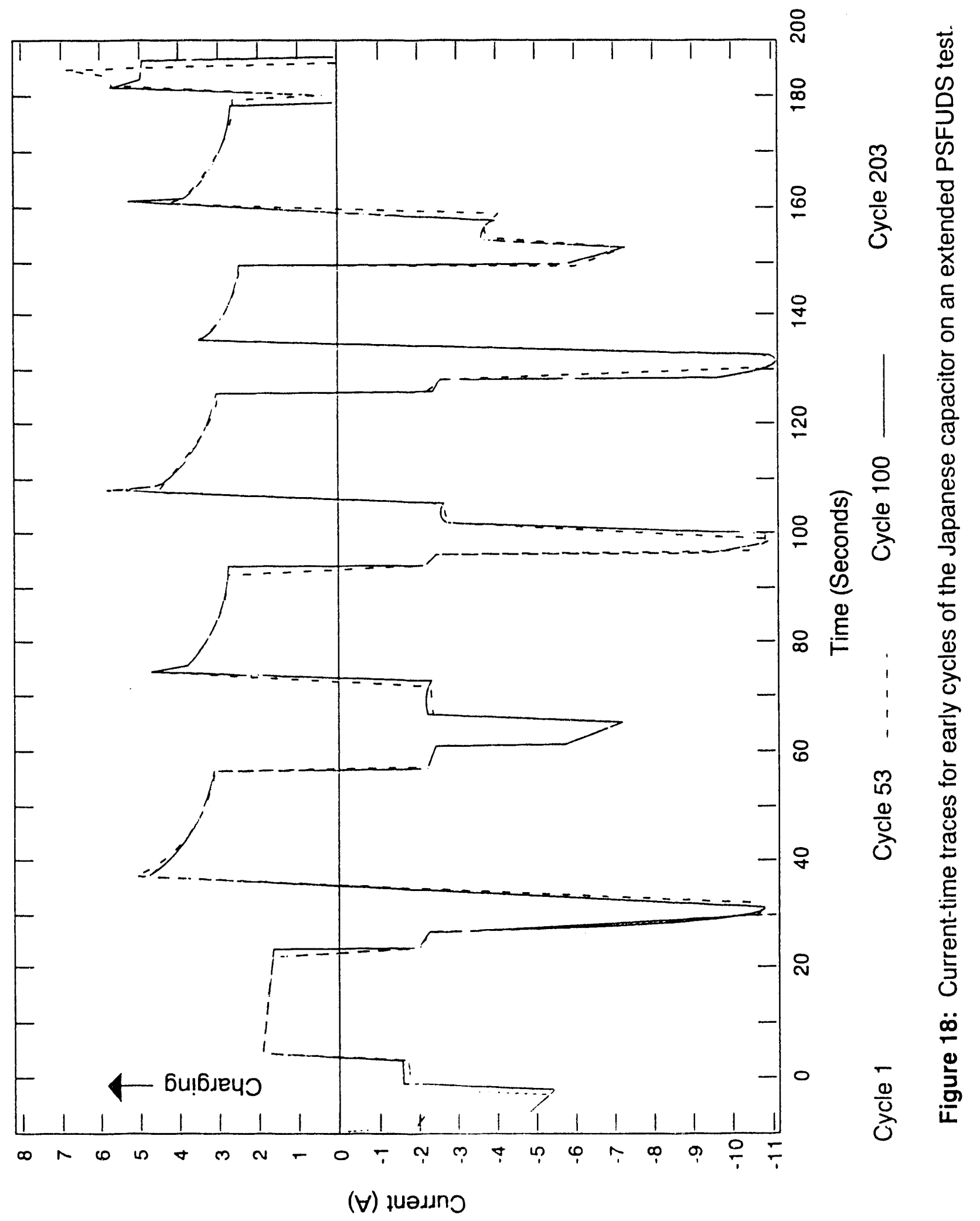






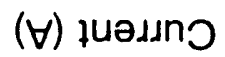




\section{Life Cycle Test}

A life cycle test of one of the Japanese capacitors was performed using the test set-up shown in Figure 7 . The capacitor was charged at a constant current of $5 \mathrm{~A}$ and discharged at a constant current of $5 \mathrm{~A}$. The peak power during these tests was $227 \mathrm{~W} / \mathrm{kg}$. The time for the complete charge/discharge cycle was 34 seconds at the beginning of life cycle test. The test was started on April 19, 1991 and was completed on June 4, 1991 after 119,j00 charge/discharge cycles. Testing was done continuously except for periods in which the test equipment was shutdown by the PC-based monitoring system. After the test set-up was debugged, the testing ran many days between shutdowns. The test was terminated after it was clear there had been a significant degradation in the performance of the capacitor. This degradation represented about a $20 \%$ decrease in the capacitance of the device.

Strip-chart traces of voltage vs. time for the charge/discharge cycle were recorded at the beginning and end of the day during the life cycle tests. A typical trace is shown in Figure 20. The traces showed a gradual reduction in cycle time in the later stages of the test from 34 seconds to 27 seconds. The characteristics of the device over the life test are summarized in Table 4. The capacitance decreased from 69 Farads to about 53 Farads and the resistance, which was calculated from the sudden voltage change as the current switched between charge and discharge, increased from 25 milliohms to 40 milliohms. This gradual degradation in capacitor performance would be expected to continue if the cycling of the device had been continued.

\section{Thermal Response Tests}

Tests were performed to measure the heat generated by the Japanese capacitor on the PSFUDS cycle. For these tests, the peak power was $300 \mathrm{~W} / \mathrm{kg}$. As shown in Figure 6, the capacitor and $500 \mathrm{gm}$ of water were put into a plastic bag. The capacitor is completely immersed in the water. The plastic bag is then placed in a thermal enclosure to minimize heat loss to the environment. The thermal enclosure containing the capacitor was put into an environmental chamber which could maintain a constant ambient temperature to within $1^{\circ} \mathrm{C}$. Before the capacitor was cycled, a calibration test was made to determine the heat loss coefficient of the enclosure. It was found that the 


\section{Charge/Discharge Current - 5/A 4:45 pm 5/23/91}



Figure 20: A strip-chart record of voltage vs. time during charge/discharge cycles of the Japanese Capacitor after about 80,000 cycles. 


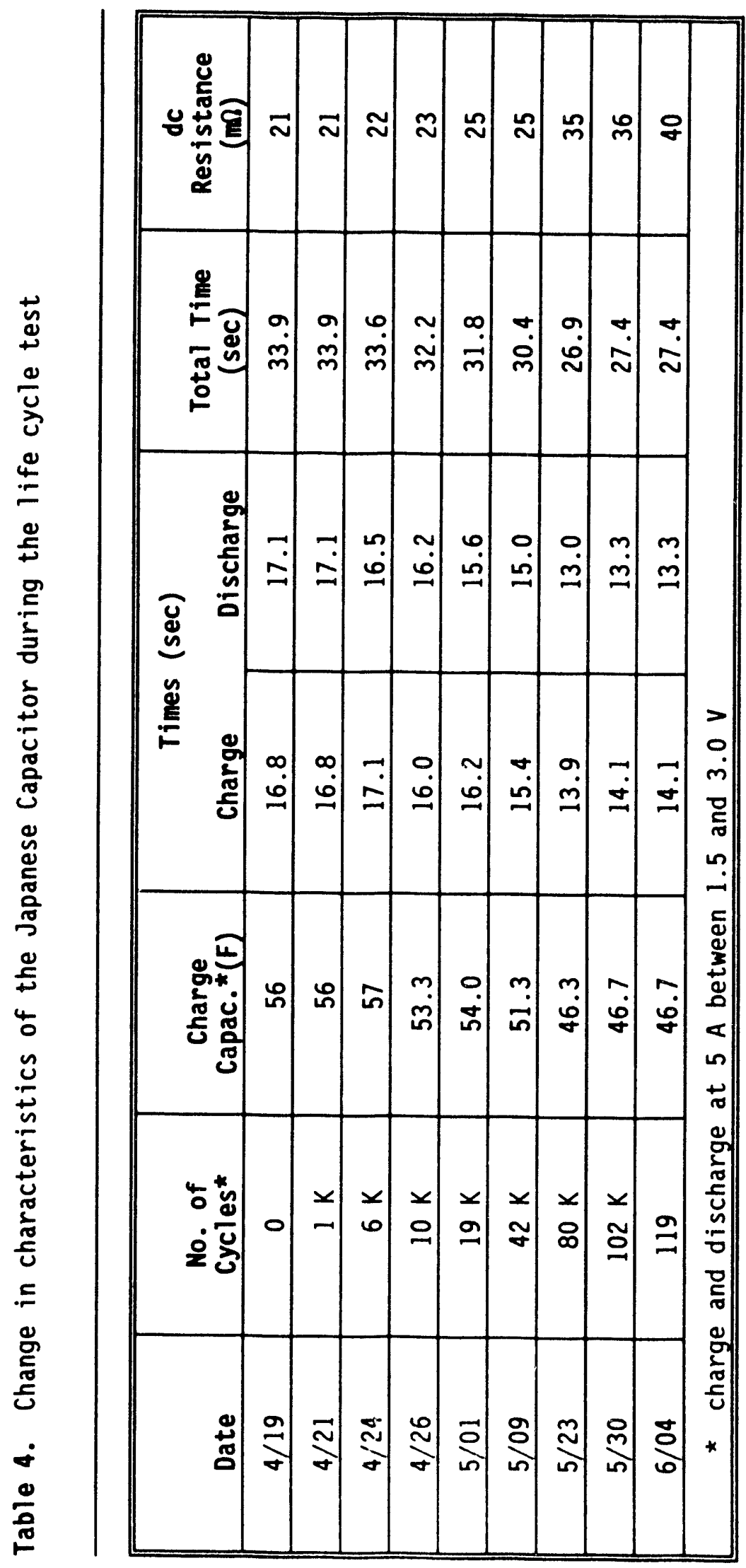


heat loss (Qloss) from the chamber could be expressed as

$$
\text { Qloss }=K *(\text { Twater }- \text { Tamb }), K=.117 \mathrm{~W} /{ }^{\circ} \mathrm{C}
$$

A summary of the enclosure thermal calibration data is given in Table 5.

When the capacitor was cycled, the water temperature increases slowly as shown in Figure 21. The heat generated $Q$ (genthm) during the cycling is equal to the heat gained by the water Qwater plus the heat lost by the water to the environment Qloss. Hence

$$
Q(\text { genthm })=Q \text { water }+ \text { Qloss (in Watts) }
$$

The heat energy generated $E$ (genelec) during the cycle can also be determined from the difference between the electrical energy $(W-s e c)$ put into the capacitor during the charge portion of the cycle Ech and the discharge energy (Edsch) taken from the capacitor during discharge. Hence

$$
E(\text { genelec })=E c h-E d s c h(\text { in } W-s e c)
$$

The efficiency (eleff) based on the electrical data for the cycle is then given by

$$
\text { eleff }=E d s c h /(\text { Egenelec }+ \text { Edsch })
$$

The rate of heat generation $Q R$ (genelec) (in Watts) is given by

$$
Q R(\text { genelec })=E(\text { genelec }) / 192 \mathrm{sec}
$$

The efficiency (theff) based on the thermal data is given by

$$
\text { theff }=E d s c h /(\text { Qgenthm* } 192+\text { Edsch })
$$

The results of the thermal tests are summarized in Table 6 . The values of the heat generated during the PSFUDS cycle calculated using the electrical 


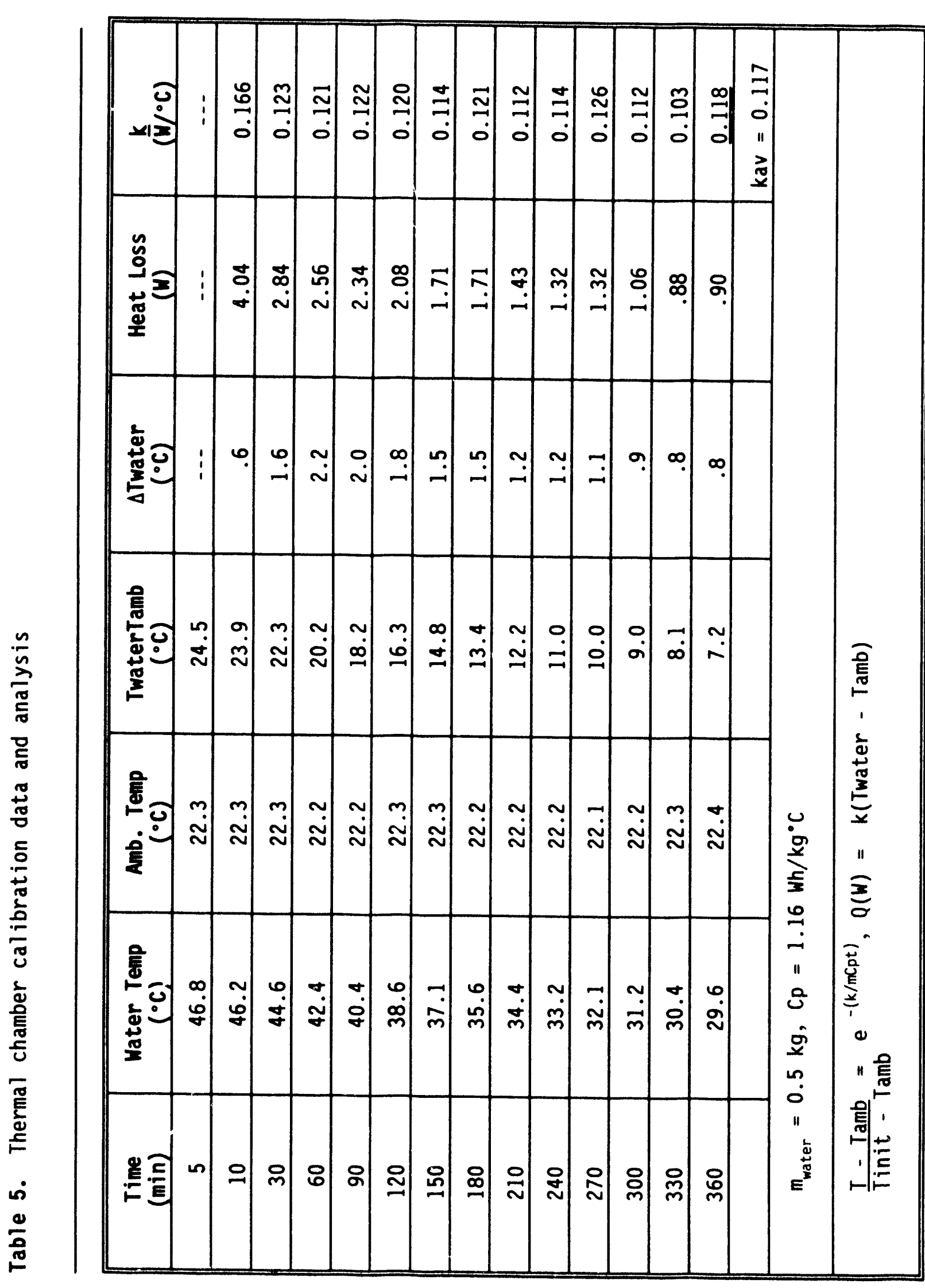




\section{Calibration of Calorimeter 2/5/91}



Figure 21: Temperature traces during the heat-loss calibration of the insulated enclosure placed in the environmental chamber. 

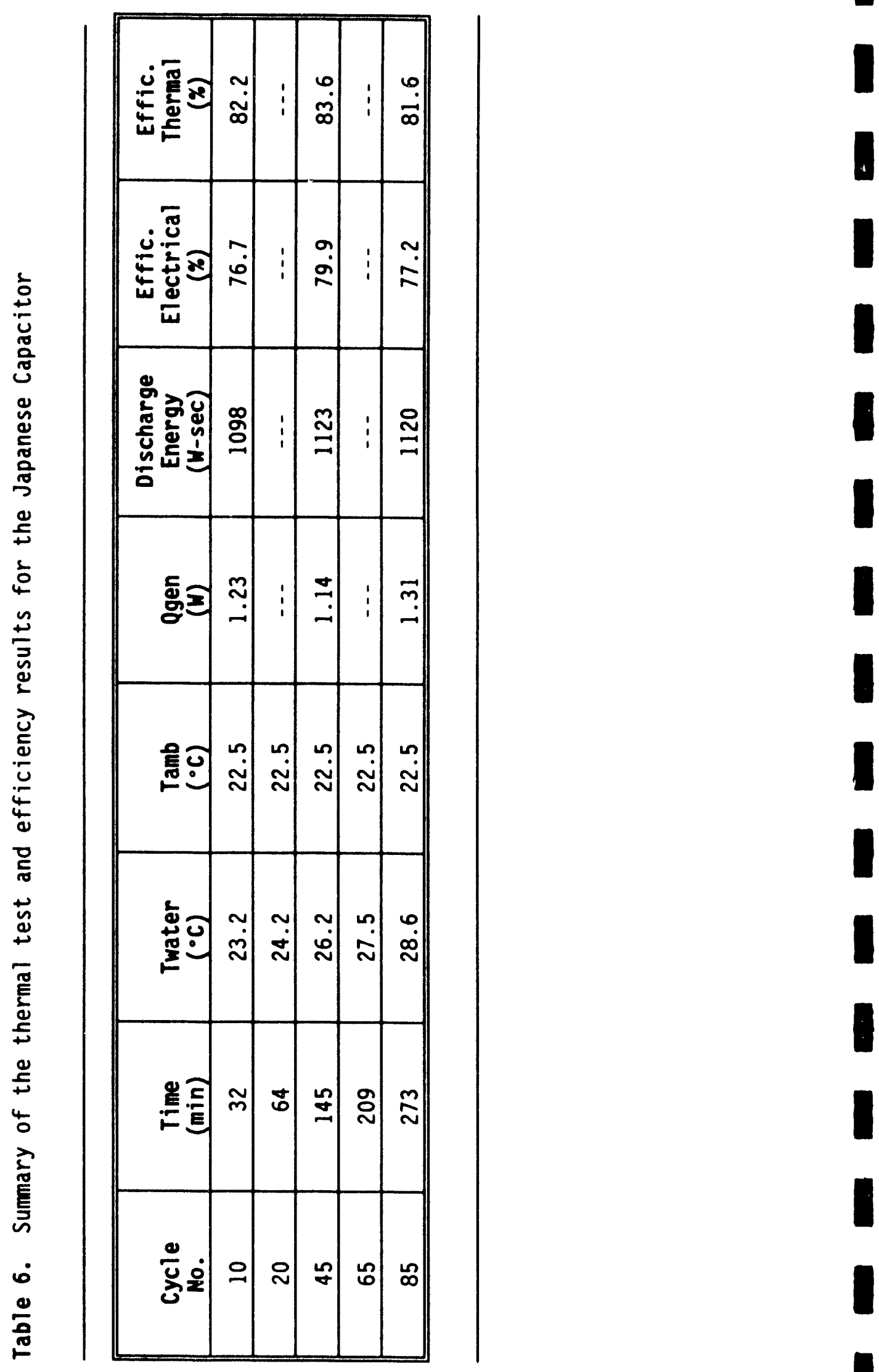
and thermal data agree to within about 15\%, with the thermal value being higher. The round-trip efficiencies determined by the two methods differ by only 2-3 points and are between 79 and $82 \%$. Using an internal resistance of 28 mohms, and measured values of $I$ during the cycle, calculated $I^{2} R$ losses account for $-80 \%$ of the heat generated during the PSFUDS cycle.

\section{The Pinnacle Research Institute Capacitor}

\section{Performance Characterisicics}

Tests of the Pinnacle Research Institute (PRI) capacitors were performed at various charge and discharge rates. The maximum voltage in all the tests was $20 \mathrm{~V}$. The minimum voltage in the discharge tests was $8.0 \mathrm{~V}$. The result of a typical $32 \mathrm{sec}$ charge at $2 \mathrm{~A}$ is given in Figure 22 as a plot of $Q$ versus $V$. The average capacitance of the PRI devices is 3.2 Farads based on the Amp-sec capacity and 3.4 Farads based on the Watt-sec capacity for the charge. The measured capacitances of the ten devices agreed well with the PRI data (Table 7) delivered with the capacitors. The capacitance of the bipolar cells is about 64 Farads with a specific capacitance of $1.2 \mathrm{~F} / \mathrm{cm} 2$ for the $1 \mathrm{~V}$ cells. Most of the testing was done using two of the ten devices (\#2 and \#9), which had capacitance near the average, but all the other devices were tested at several power levels to deternine the variability among the devices. As shown in Table 8 , the variability is about $10 \%$. The devices were fabricated in the laboratory at PRI and represented the state-of-the-art that could be fabricated in small quantities at an affordable cost as of September 1990. Higher energy density devices are being fabricated at PRI as part of their ongoing research and development program.

The PRI capacitors were discharged at constant powers between 25 and $300 \mathrm{~W}$. The corresponding power densities (W/kg) are 125 and 1400 . The results of the discharge tests are given in Figures 23 and 24 . The $Q$ versus $V$ plots in Figure 23 show that the discharge is rate dependent and that there is a significant departure from linearity especially at lower states-of-charge of the capacitor. The fraction of the charge recovered duriny discharge from 20 to $8 \mathrm{~V}$ is less than the $60 \%$ expected based on ideal capacitor behavior. The fraction of the energy stored in the capacitor that is recovered in the 




Figure 22: Charge - voltage characteristi 2 of the PRI capacitor. 





Table 8. Variability of the Pinnacle Research Institute devices (measured by INEL)

\begin{tabular}{|c|c|c|}
\hline PRI Device * & $\begin{array}{c}\text { Charge Q0* } \\
(A-s e c)\end{array}$ & $\begin{array}{c}\text { Energy Eo* } \\
(\mathrm{H}-\mathrm{sec})\end{array}$ \\
\hline 1 & 65 & 714 \\
\hline 2 & 66 & 702 \\
\hline 3 & 60 & 645 \\
\hline 4 & 70 & 753 \\
\hline 5 & 59 & 627 \\
\hline 6 & 60 & 630 \\
\hline 7 & 65 & 708 \\
\hline 8 & 67 & 711 \\
\hline 9 & 65 & 687 \\
\hline 10 & $\begin{aligned} & \frac{64}{64 \pm 4} \\
c= & 3.2 \pm 0.2\end{aligned}$ & $\begin{aligned} & \frac{693}{687 \pm 40} \\
C= & 3.4 \frac{42}{2} \pm 0.2\end{aligned}$ \\
\hline
\end{tabular}




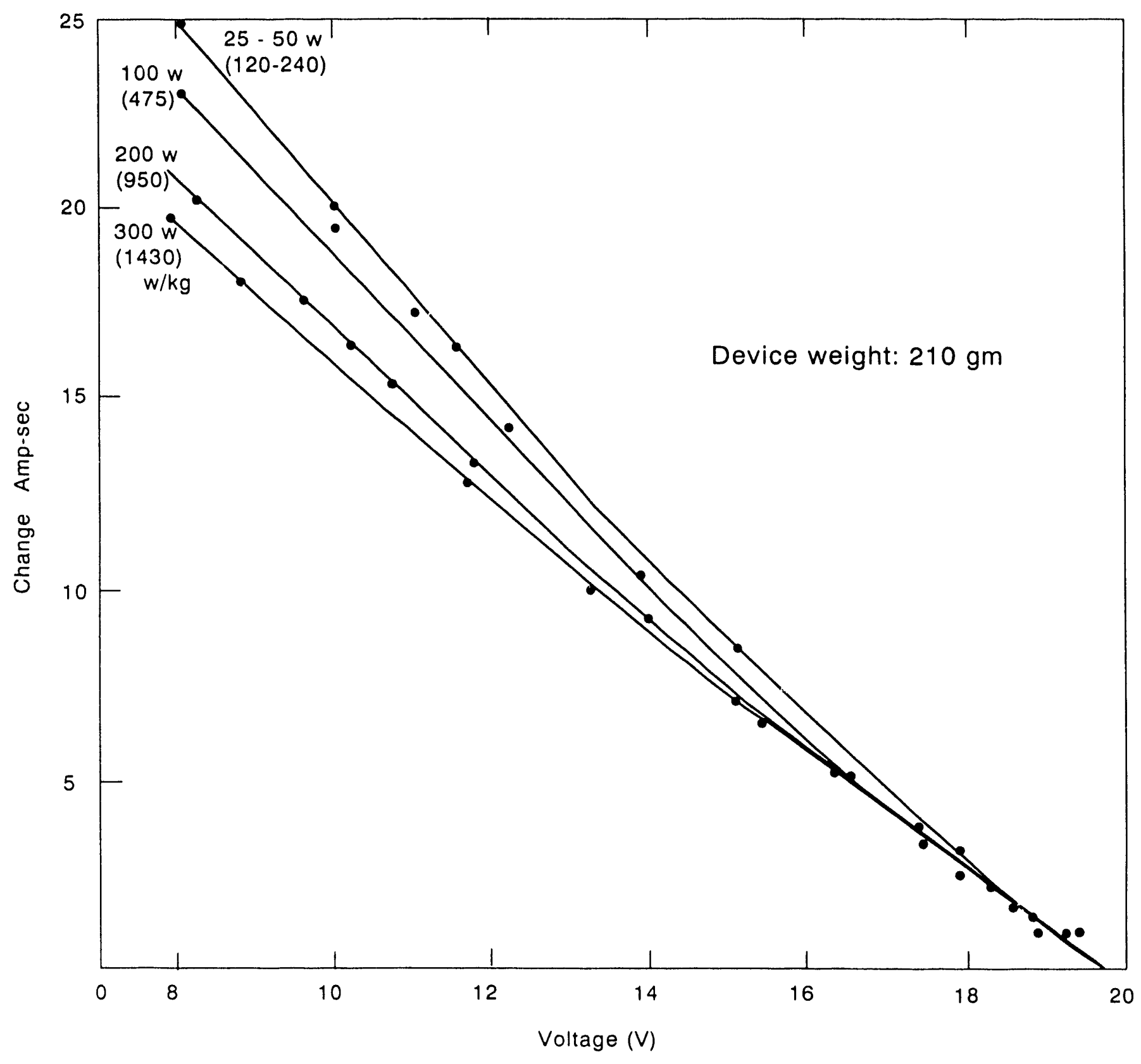

Figure 23: Charge-voltage characteristics of the PRI capacitor for various constant power discharges. 


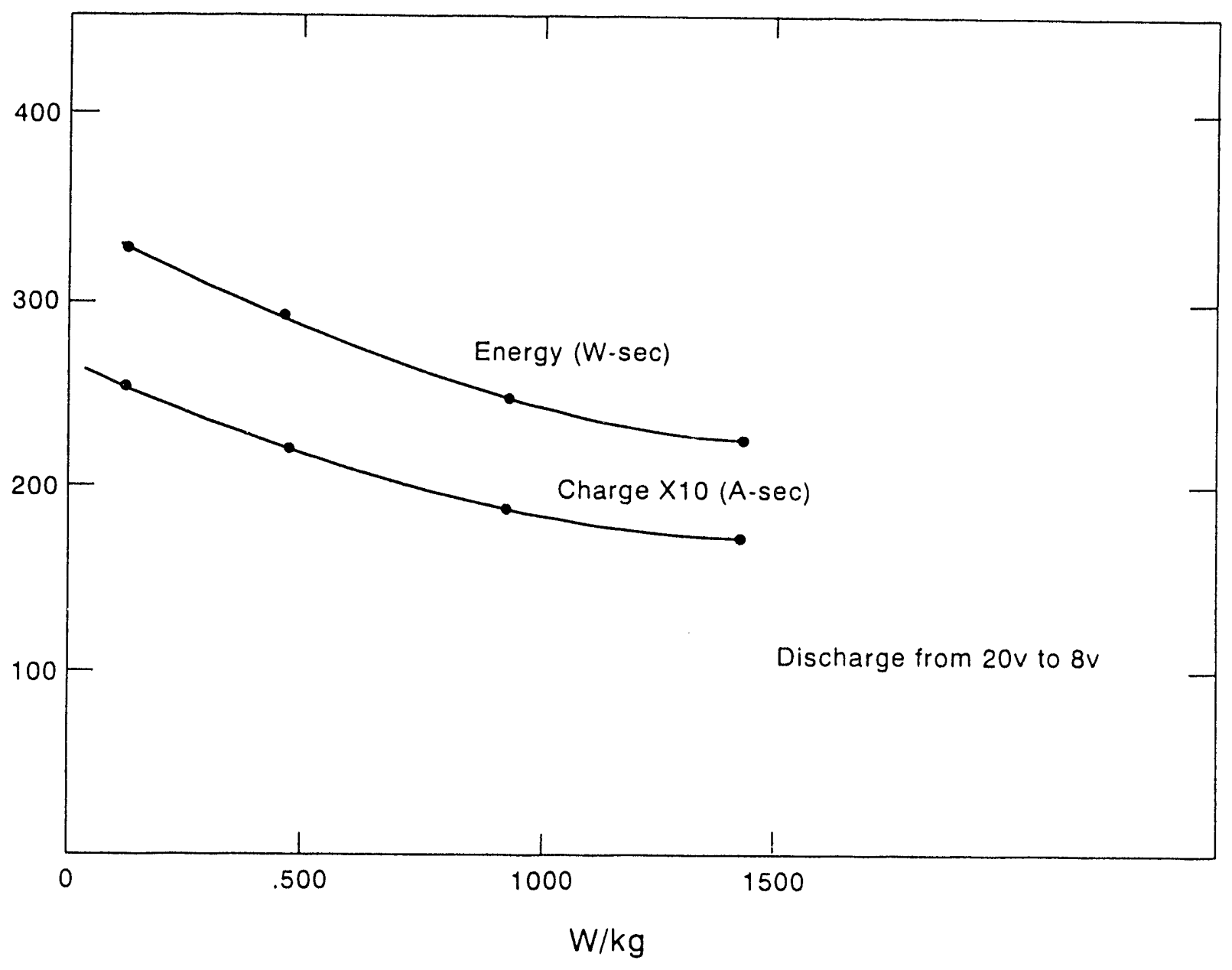

Figure 24: Rate dependency of the energy and charge capacity of the PRI capacitors for discharge at various constant power densities. 
discharge is also less than the $84 \%$ expected using the simple relation $E / E O=$ $\left(1-\left(V_{c} \backslash V_{0}\right) 2\right)$. The charge $(2 \mathrm{~A})$ and discharge $(25 \mathrm{~W})$ curves given in Figure 25 indicate the hysteresis behavior of the capacitor which results in the recovery of a disportionate fraction of the charge and energy at voltages below $8 \mathrm{~V}$. The reason for this behavior is not understood at the present time. Figure 26 indicates that the Japanese capacitor exhibited a similar hysteresis behavior.

The magnitude of the rate dependency of the capacity of the PRI devices is less than for the Japanese capacitors. This is shown in Figure 27 in which the rate dependence of energy capacity $E$ of the Japanese and PRI capacitors are given as a function of power density for discharges between $v_{0}$ and $1 / 2$ vo. The PRI devices show a reduction in capacity of less than $20 \%$ out to a power density of about $500 \mathrm{~W} / \mathrm{kg}$. This additional power capability was not used in the PSFUDS tests of the PRI devices, because the short test times at the higher powers were not compatible with the capability of the Bitrode tester.

Measurements were made of the resistance of the PRI capacitors with the ac impedance bridge at frequencies between $10 \mathrm{~Hz}$ and $1 \mathrm{kHz}$. The results are given in Figure 28 as a $\log -\log$ plot, which permits extrapolation of the data to very low frequencies. As shown in Figure 28, the resistance of the PRI device is more frequency dependent than that of the Japanese capacitor. The PRI capacitor is bipolar with 20 cells in series. The resistance per cell is only several milliohms. It was not possible to determine with good confidence the dc resistance of the PRI capacitors using the charge/discharge data. Voltage steps at the initiation of charge and discharge were evident in the data, but the resistances inferred from the steps were inconsistent. In most cases, the resistances inferred from the discharge data were much lower than the values shown in Figure 28, while the resistances inferred from the charge data were higher.

Tests were also performed to determine how well the PRI capacitor holds a charge after being charged to $20 \mathrm{~V}$ and to measure the magnitude of the voltage recovery after the capacitor is completely discharged to $0.0 \mathrm{~V}$. It 


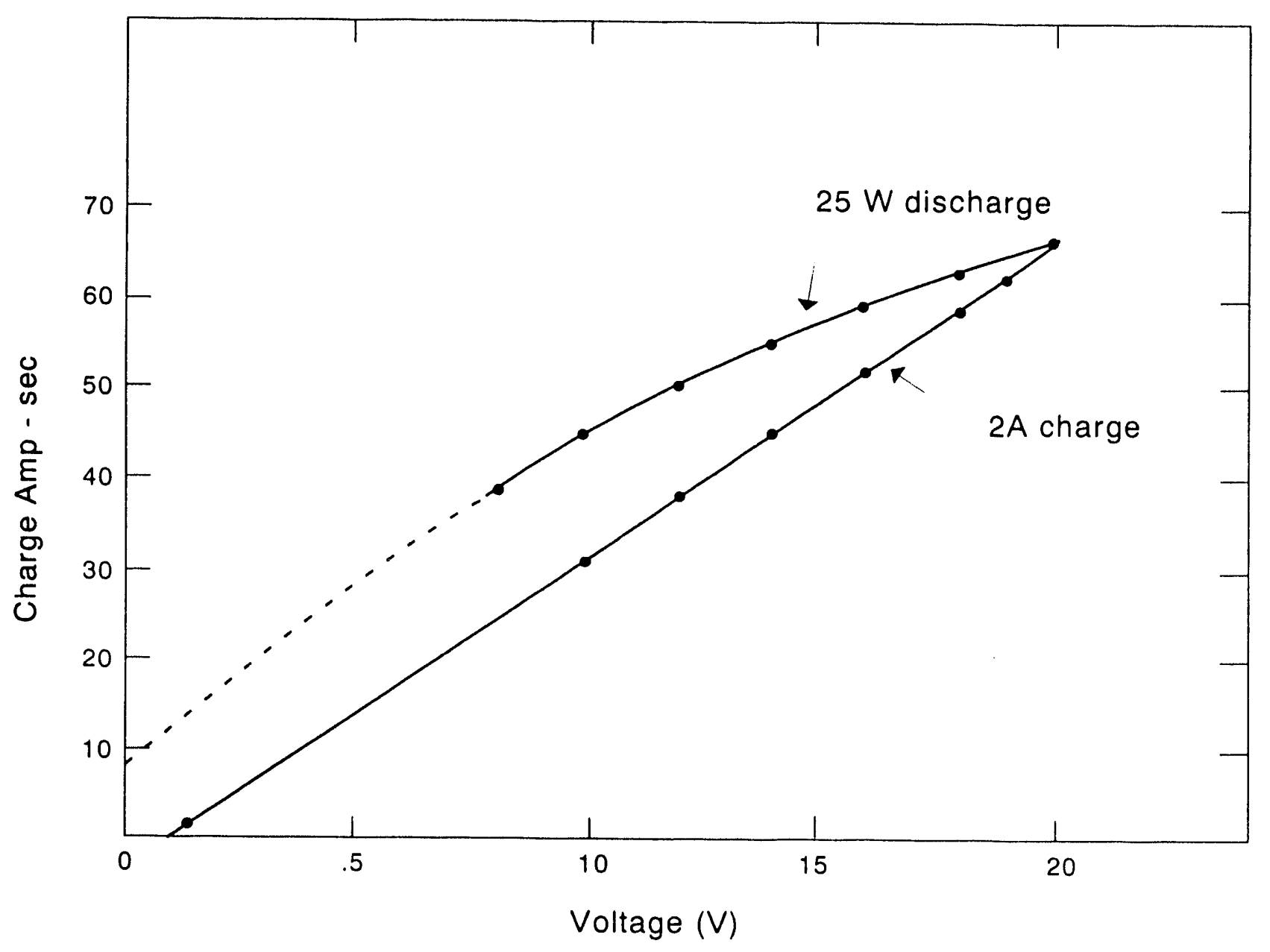

Figure 25: Hysterisis in the $Q$ vs $V$ plot for the PRI capacator. 


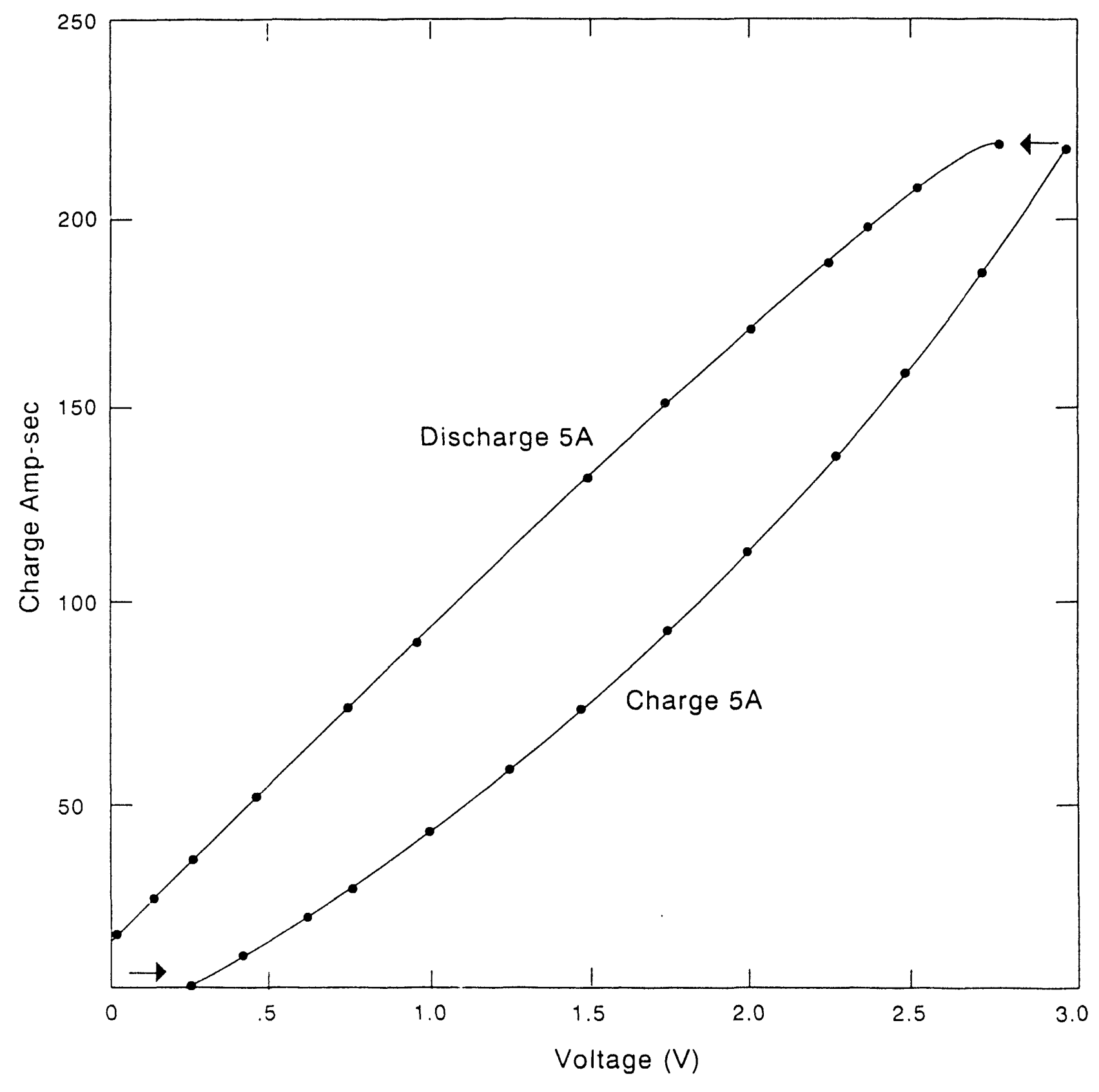

Figure 26: Hysterisis in the $Q \vee v \vee$ plot for the Japanese capacitor. 


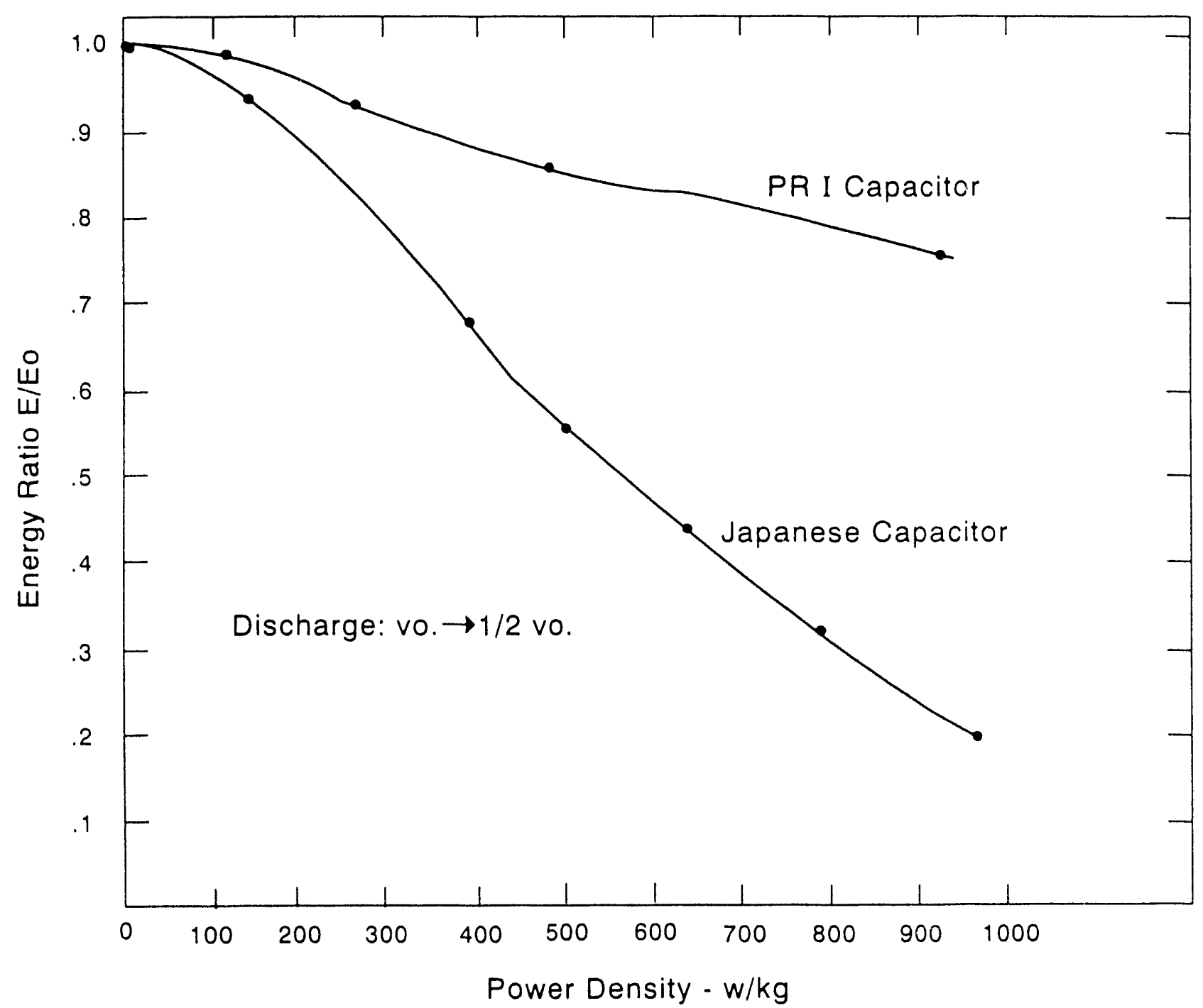

Figure 27: Comparison of the rate dependency in discharge of the Japanese and PRI capacitors. 


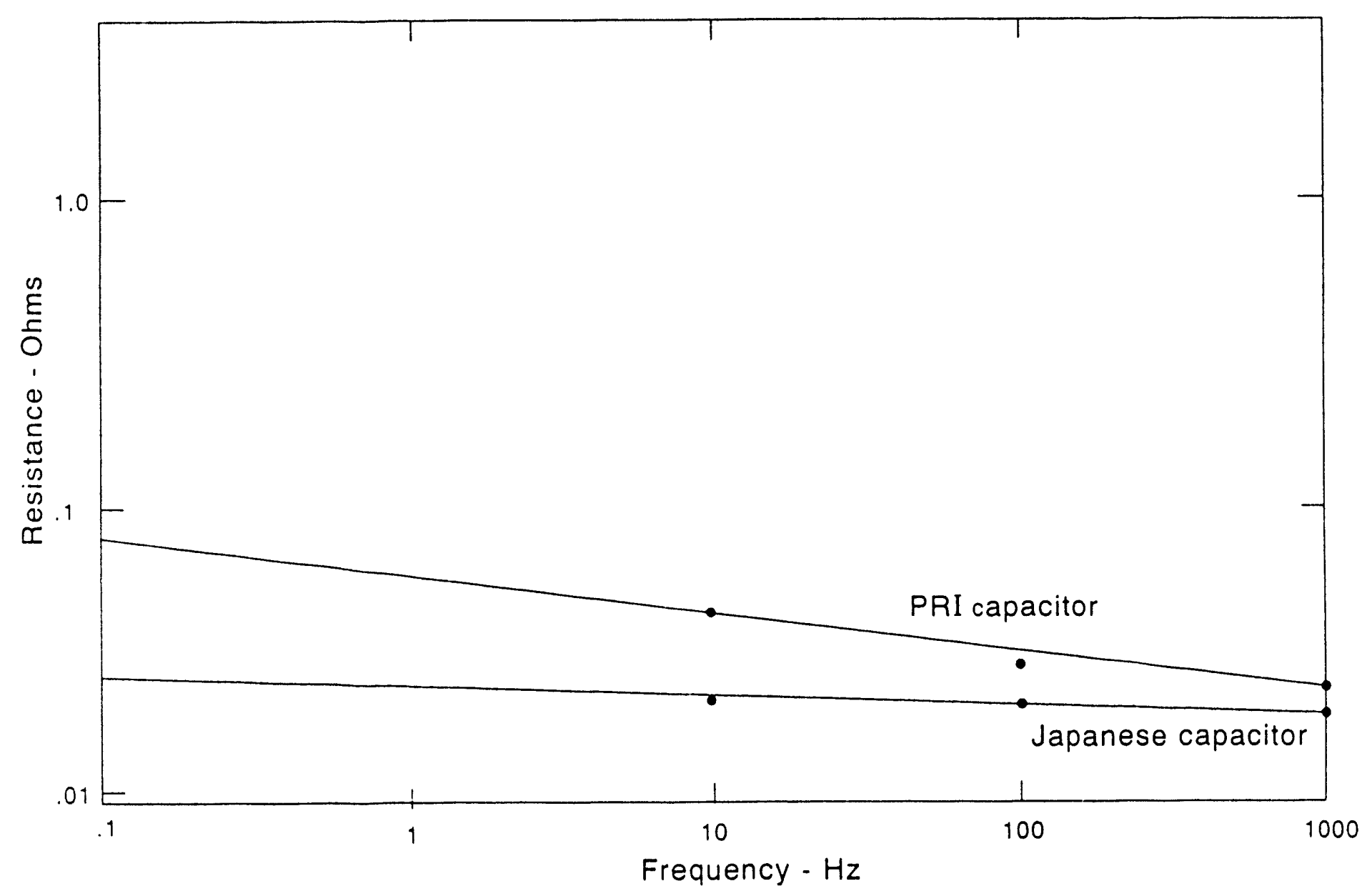

Figure 28: Resistance of the Japanese and PRI capacitors as a function of frequency. 
seems reasonable to expect that the voltage decay after charging is related to leakage current and the devices with a high leakage current would show a significant voltage decay. Information from PRI (Table 7) indicated the capacitors had a relatively high leakage current of 30-80 mA. Figure 29 shows the voltage decay as a function of time up to 300 seconds after a charge to $20 \mathrm{~V}$. As expected the voltage decay after charging was significant and for that reason, all discharge tests were initiated with no rest period after reaching $20 \mathrm{~V}$. The primary reason for the high leakage current is that the assembly techniques used for the present devices permit impurities to enter the devices during assembly resulting in electrochemical reactions unrelated to the double-layer charge/discharge mechanisms. Even in the absence of impurities, some voltage decay would occur due to equilibration of the concentration gradients in the device when no current is flowing. More recent PRI devices have much lower leakage current.

The voltage recovery after a $25 \mathrm{~W}$ discharge to $0.0 \mathrm{~V}$ is given in Figure 30. The initial part of the recovery is rapid, but the recovery continues at a slower rate for 5-6 minutes after the end of the test. Voltage recovery was noted after all the discharge tests regardless of the voltage at termination.

\section{PSFUDS Cycle}

The PRI capacitors were tested on a PSFUDS cycle much like that used for testing the Japanese capacitors (Table 2). In the tests of the PRI capacitors, it was necessary to divide the power densities $(\mathrm{W} / \mathrm{kg})$ in Table 2 by two before calculating the discharge power profile even though the PRI capacitors had higher power capability than the Japanese capacitors. This was necessary, because the PRI capacitors store less energy per unit mass. The useable energy density of the PRI device; was $0.4 \mathrm{Wh} / \mathrm{kg}$ compared to $0.8 \mathrm{Wh} / \mathrm{kg}$ for the Japanese capacitors. The alternative to reducing the $\mathrm{W} / \mathrm{kg}$ for each time step would have been to reduce the duration of each time step in the PSFUDS cycle by a factor of two. This more attractive alternative was not possible, because the Bitrode tester could not control with satisfactory 


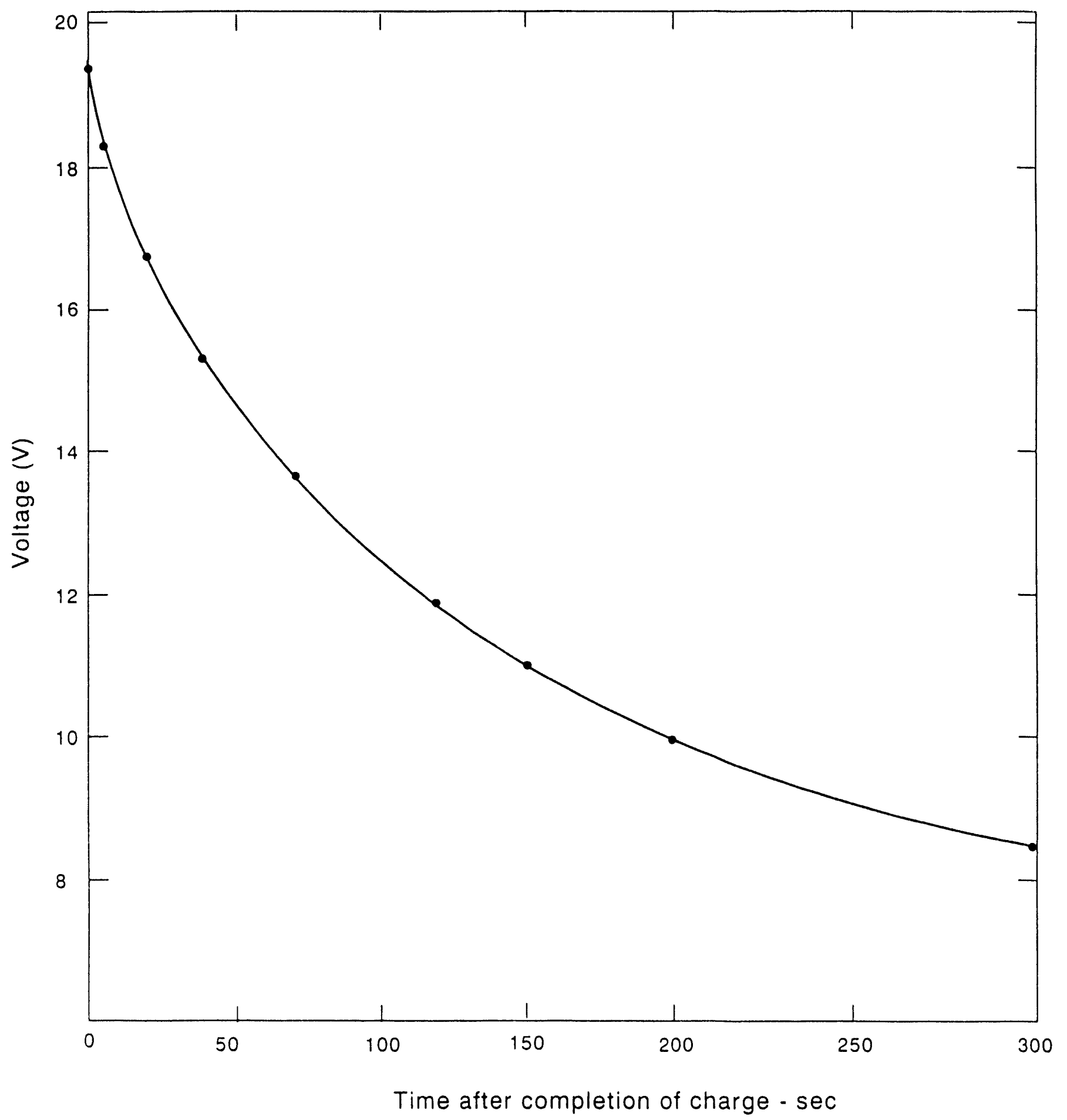

Figure 29: Voltage decay of the PRI capacitor after a $2 \mathrm{~A}$ charge to $20 \mathrm{~V}$. 


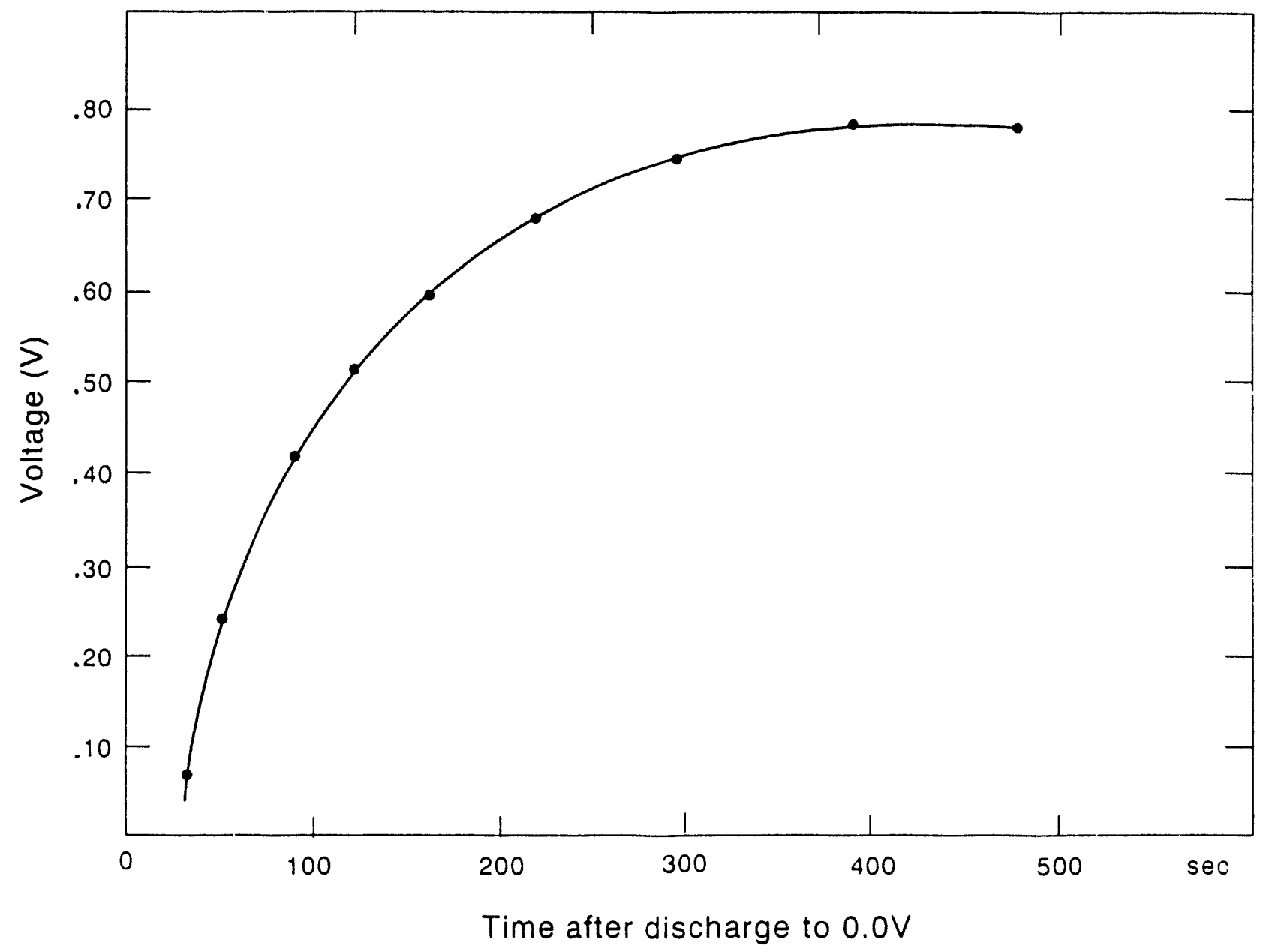

Figure 30: Voltage recovery of the PRI capacitor after a discharge to $0.0 \mathrm{~V}$. 
accuracy the discharge power using the smaller time steps. Hence the maximum power in the PSFUDS tests of the PRI capacitors was only $32 \mathrm{~W}$ rather than the 80-100 W that the devices could have easily supplied. Nevertheless, the PSFUDS tests did show that the PRI capacitors could function satisfactorily in a cycle with repeated charge/discharge subcycles as required in electric vehicle applications, in which the main battery is load leveled.

PRI capacitors \#2 and \#7 were tested in parallel on the modified PSFUDS cycle. The tests were run for up to 150 cycles (about 8 hours continuously). The results for cycles 5, 50, and 150 are shown in Figures 31-33. At the beginning of the test, the current (power) was shared fairly equally between the two capacitors, but as the test proceeded capacitor \#2 camried an increasing fraction of the load. The test was terminated at cycle 150 when the differences in current between the two capacitors became large. Capacitor \#2 was used in subsequent PSFUDS and life cycle testing, because it proved to have a longer life than most of the PRI devices.

The temperatures of the two capacitors during the PSFUDS tests are given in Table 9. The temperatures increased to a maximum of about $35^{\circ} \mathrm{C}$ or $10^{\circ} \mathrm{C}$ above the ambient. This temperature increase was greater than that found for the Japanese capacitors even thougit the average power density of the tests with the Japanese capacitors was twice that for the PRI device tests. The electrical round-trip efficiency of the PRI capacitors on the PSFUDS was calculated from the electrical data. It was found that the efficiency was 75-80\% with the efficiency tending to decrease slightly at the higher cycle counts. It was not possible to relate the round-trip efficiency to the temperature rise, because the magnitude of the heat loss to the environment was not known. Thermal response tests were performed with the PRI capacitors using the same test setup and procedures used for the thermal tests of the Japanese capacitors. Those results are discussed later. The PSFUDS testing of the PRI devices was straight forward with the only problem being their relatively short cycle life. 


\section{Pinnacle Research $20 V$ Devices}

\section{Cycle 5}

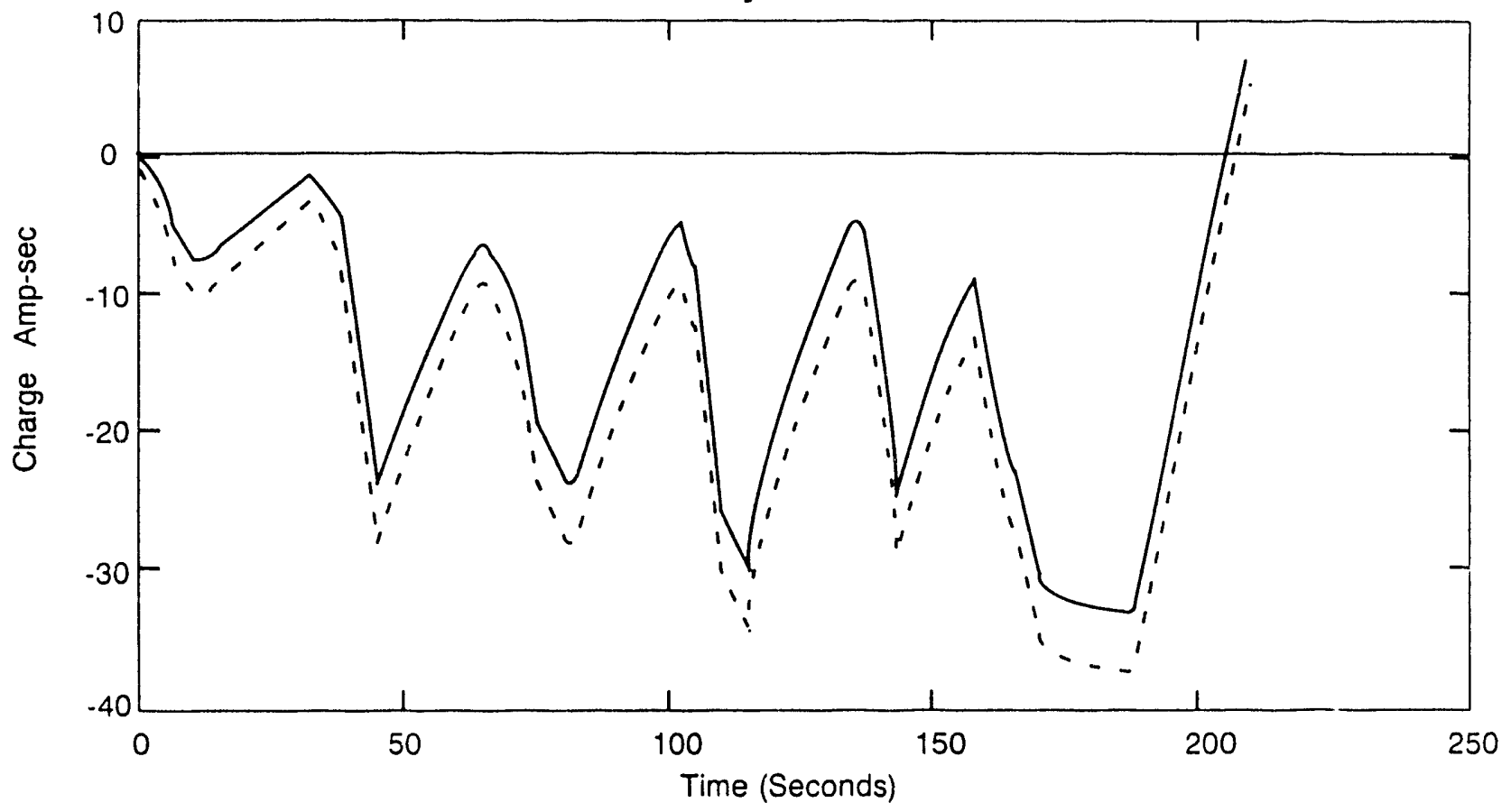

_. . Cap \#2

Cap \#7

\section{Cycle 5}

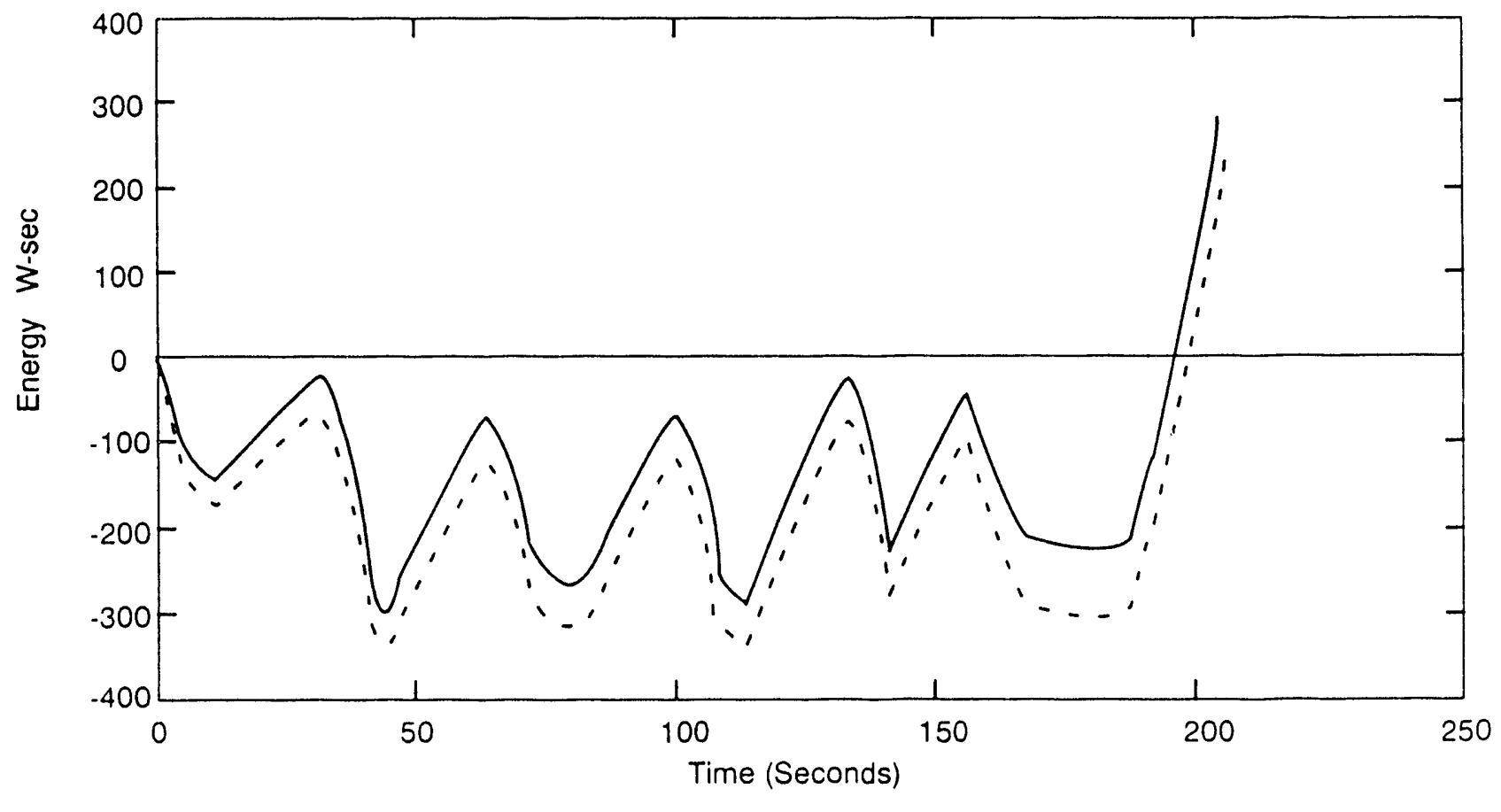

_. . Cap \#2 Joules

- Cap $=7$

Figure 31: Load sharing between two PRI capacitors during a PSFUDS test (cycle 5). 


\section{Pinnacle Research 20V Devices}

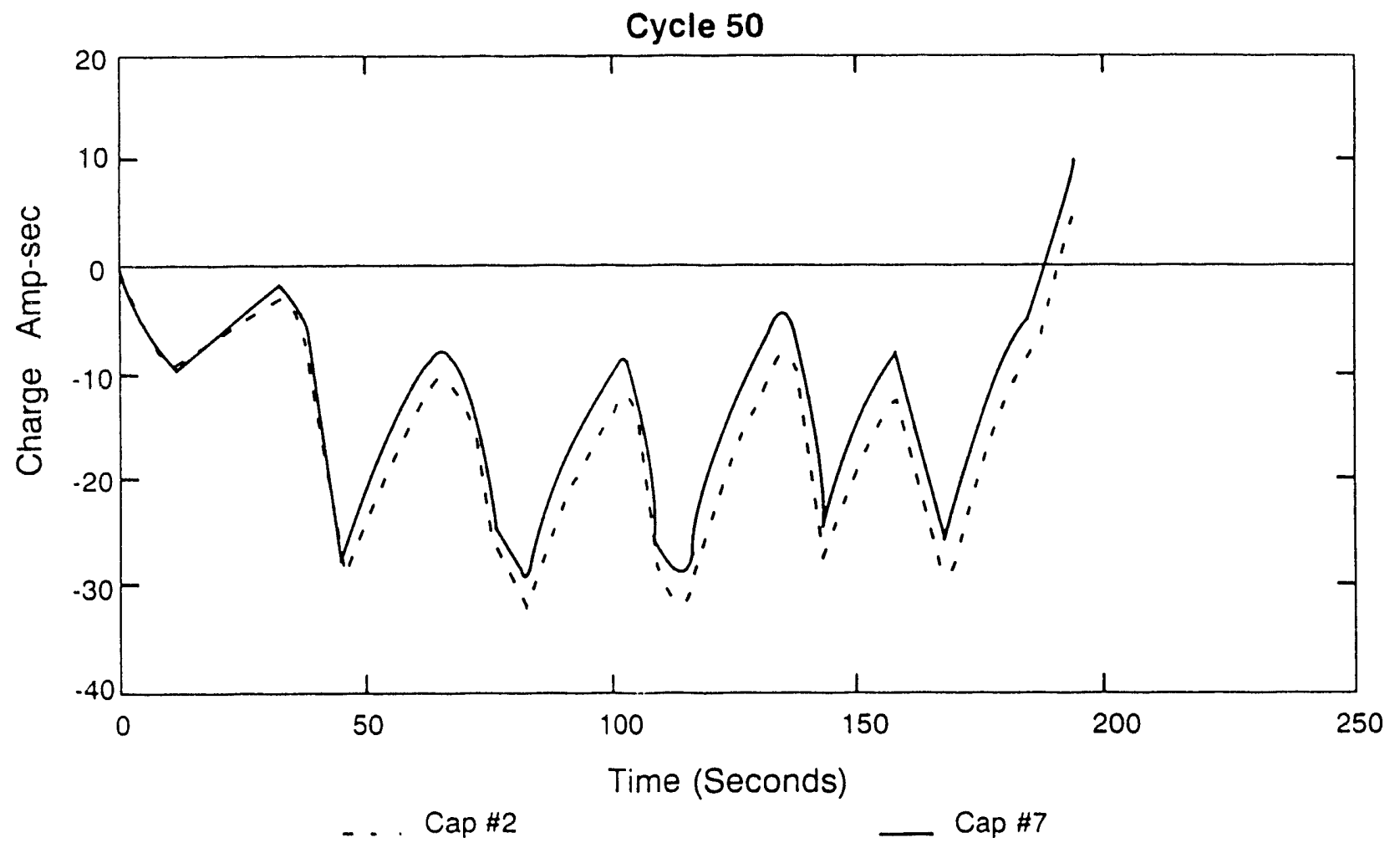

Cycle 50



Figure 32: Load sharing between two PRI capacitors during a PSFUDS test (cycle 50). 
Pinnacle Research 20V Devices

Cycle 150

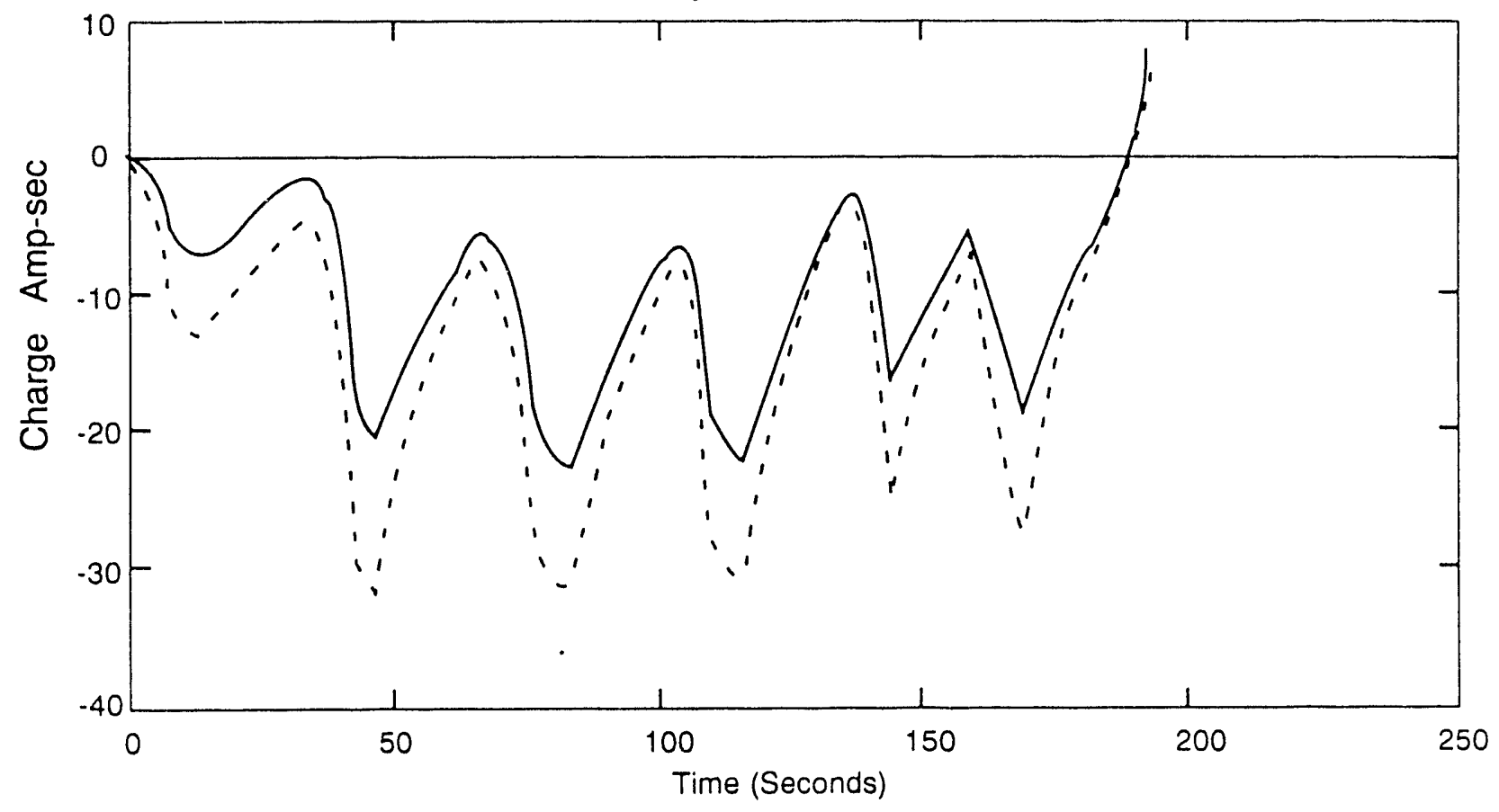

- . Cap \#2

Cap \#7

\section{Cycle 150}

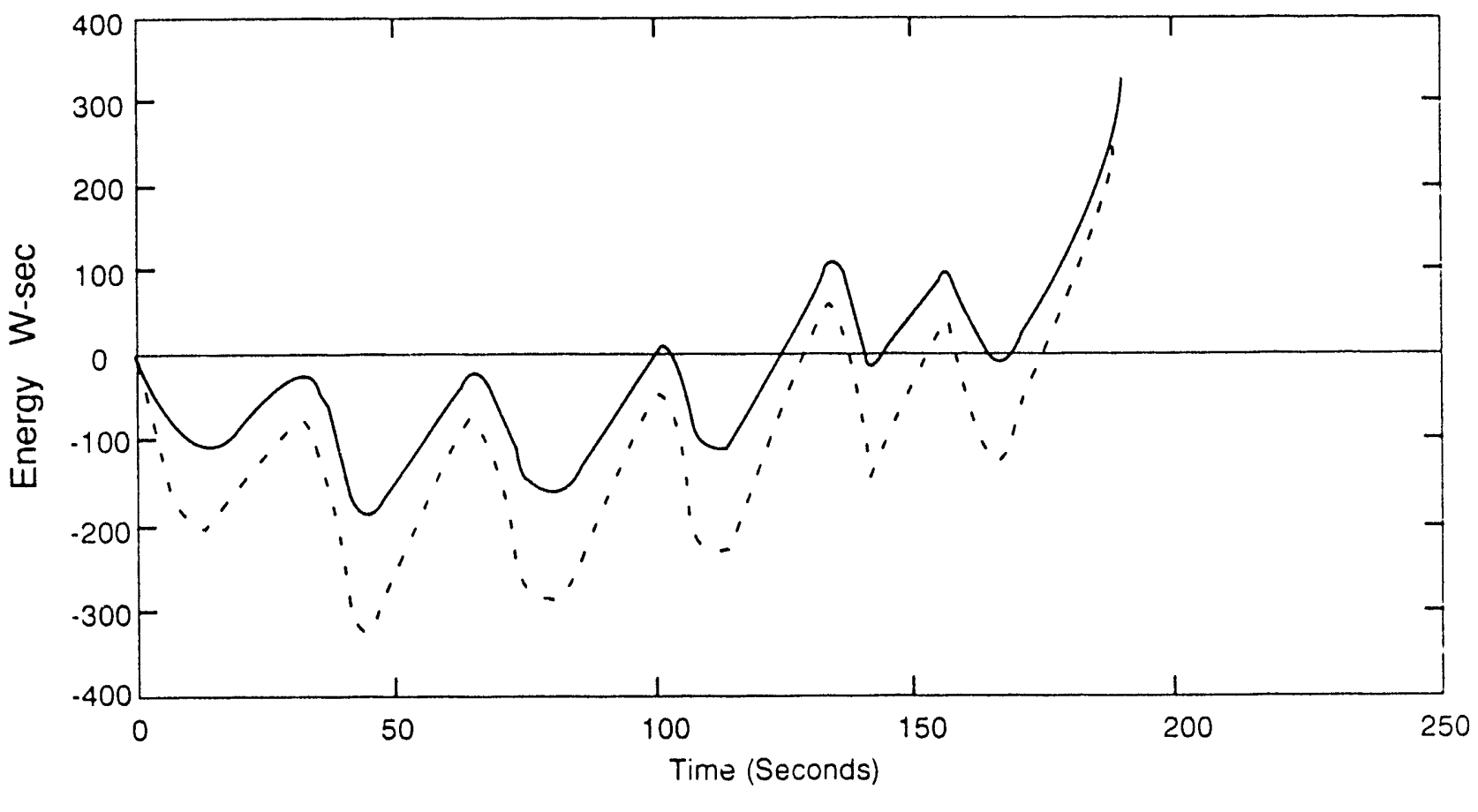

_. Cap \#2

Cap $\# 7$

Figure 33: Load sharing between two PRI capacitors during a PSFUDS test (cycle 150). 
Table 9. Temperature increase of the PRI devices during an extended PSFUDS test.

\begin{tabular}{|c|c|c|c|}
\hline \multirow{2}{*}{$\frac{\text { Cycle }^{*}}{1}$} & \multicolumn{2}{|c|}{$\underset{\# 2}{\text { Capacitor Temperatures }\left({ }^{\circ} \mathrm{C}\right)}$} & \multirow{2}{*}{$\frac{\text { Tamb }-{ }^{\circ} \mathrm{C}}{27.0}$} \\
\hline & 26.6 & 26.4 & \\
\hline 10 & 29.6 & 29.3 & 25.5 \\
\hline 20 & 31.3 & 30.9 & 25.0 \\
\hline 30 & 31.9 & 31.9 & 24.2 \\
\hline 50 & 30.6 & 31.9 & 22.3 \\
\hline 70 & 30.9 & 33.3 & 22.3 \\
\hline 100 & 32.9 & 34.5 & 24.0 \\
\hline 113 & 33.3 & 35.0 & 24.0 \\
\hline 150 & 34.4 & 35.8 & 24.5 \\
\hline
\end{tabular}




\section{Life Cycle Tests}

An attempt was made to life cycle test the PRI capacitors using the same test setup and procedures discussed previously for the Japanese capacitors. Tests were initiated using a number of the devices, including capacitor \#2, and in each case the device failed or showed large degradation in capacity after at most a day or two of testing (several thousand cycles). The ten devices were then returned to PRI for their inspection and analysis. No information has been received as yet from PRI concerning the reasons for the shorter than expected life of their devices. Recently PRI sent two small capacitors $(2 \mathrm{~cm} 2)$ to INEL on loan for cycle life testing. These devices are of improved design and had been tested by PRI for 15000 cycles. Life cycle testing of the new devices is currently underway and initial results indicate they do have much longer life. A $10 \mathrm{~V}$ device sustained 21,000 additional cycles at INEL before it showed significant degradation, and a $60 \mathrm{~V}$ device sustained about 120,000 cycles before failure.

\section{Thermal Response Tests}

Tests were performed to measure the heat generated by PRI capacitor \#2 on the modified PSFUDS cycle. The test setup and procedures developed during the testing of the Japanese capacitors were used in these tests. The results of the tests are summarized in Table 10. It was found that the round-trip efficiency of capacitor \#2 determined from the thermal measurements was between $75-80 \%$, which is in good agreement with values obtained from the electrical data obtained in the thermal tests and previous PSFUDS tests. Analysis of electrical data taken during the life cycle tests of the $10 \mathrm{~V}, 2$ cm2 device showed a round-trip charge/discharge efficiency of about $90 \%$ for a $10 \mathrm{~mA}$ charge/discharge cycle of the 0.04 Farad device. 


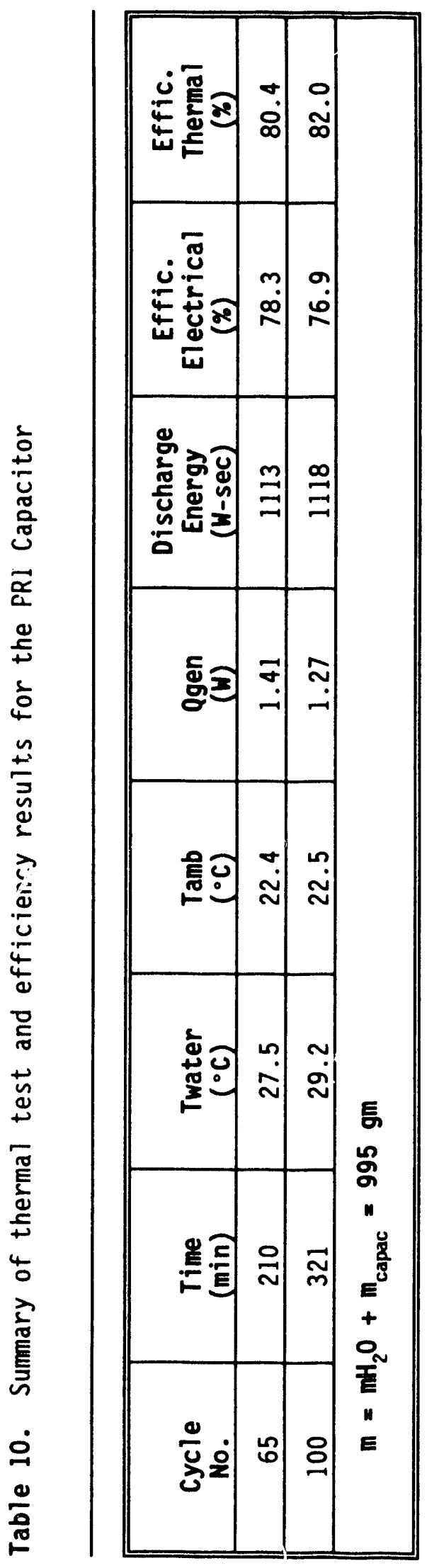




\section{THE STATUS OF HIGH ENERGY DENSITY CAPACITOR TECHNOLOGY}

The test results discussed in the previous sections permit an assessment of the present status of high energy density technology as it relates to the requirements for electric vehicle applications. This assessment will include the commercially available product-Supercap-from NEC Electronics. There is considerable technical information available on the NEC Supercap (References 4-6). It is a carbon-based device that utilizes sulfuric acid as the electrolyte and consists of 5-6 $1 \mathrm{~V}$ cells in a bipolar configuration. This type of packaging is similar to that envisioned for the ultracapacitors for electric vehicles. The largest of the Supercap devices marketed by NEC are rated at a capacitance of 1-2 Farads. The performance characteristics of the NEC Supercap and the Japanese and PRI high energy density capacitors studied in the present program are summarized in Table 11. All of these devices have energy densities that are 1-2 orders of magnitude higher than conventional electrolytic capacitors. The values for the Japanese and PRI devices have been confirmed by the INEL tests, but the values given for the NEC Supercap capacitors are based on the manufacturers rating information. The Supercap devices were not tested in the present program. All the energy density values (Wh/ $\mathrm{kg}$ and $\mathrm{Wh} / 1$ ) are based on the energy stored when the device is charged from $0.0 \mathrm{~V}$ to its rated voltage $(E=1 / 2 \mathrm{CV} 2)$. The present study has shown that about one-half of that energy is useful for battery load-leveling in the electric vehicle application.

The information given in Table 11 shows that the energy densities of the Japanese and PRI advanced capacitors are 3-10 times greater than that of the commercially available NEC Supercaps. Also the resistances (milliohms-cm2) of the advanced capacitors are several orders of magnitude lower than the NEC Supercaps, which are intended for low power applications (IC memory backup). The trade-off between energy density and resistance is clearly shown in the characteristics of the various NEC devices. Information given in the literature for the NEC Supercaps indicates they have a much lower leakage current than the advanced devices and can hold a significant fraction of their charge voltage for many hours (100-1000 hours). 


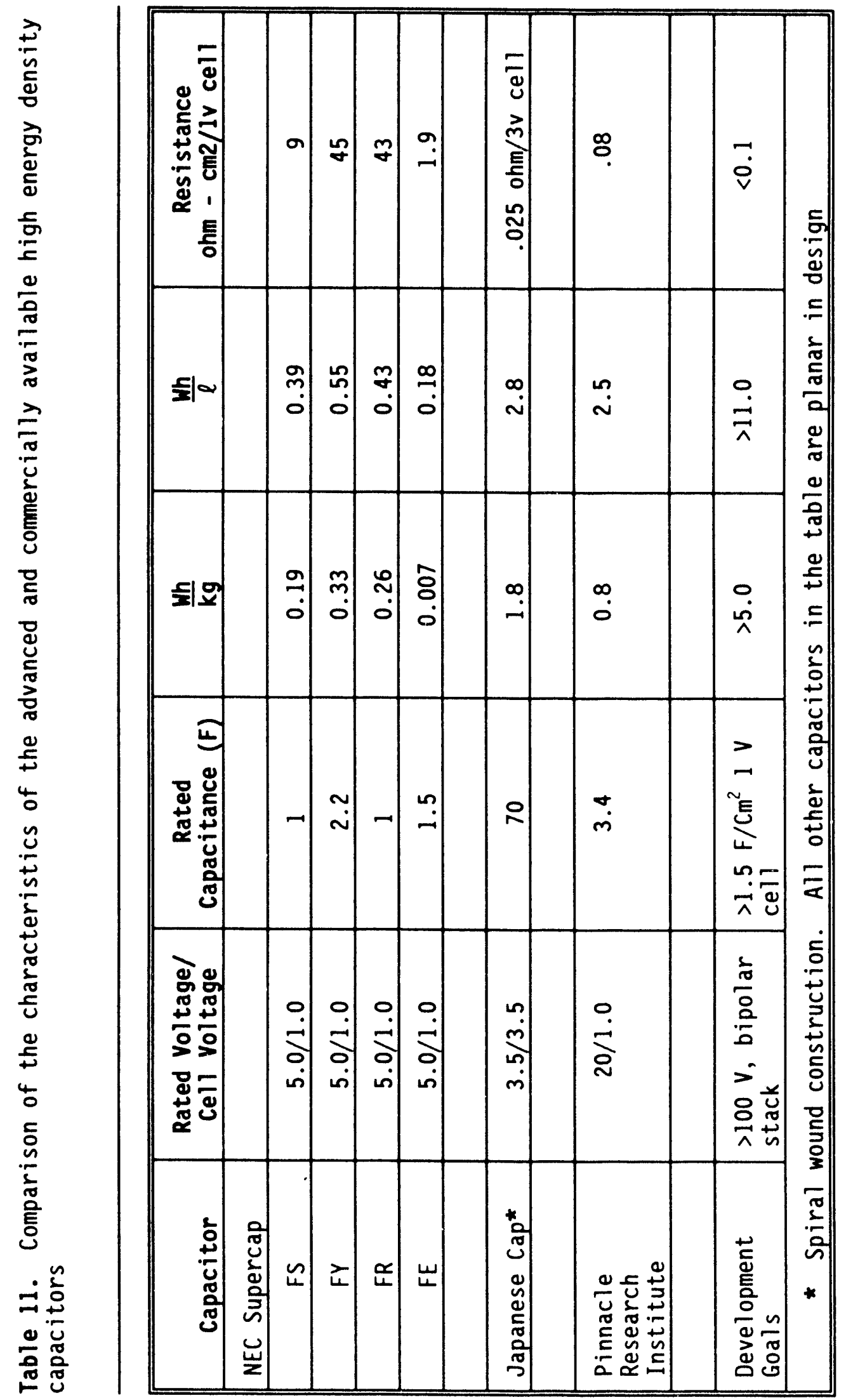


It is of interest to compare the performance characteristics of the various capacitors given in Table 11 with the requirements for the electric vehicle application given in Table 1. The data for the advanced Japanese and PRI capacitors indicate that an improvement of at least a factor of four (4) in energy density is needed to meet the energy storage requirements. This improvement in energy density must be made without an increase in resistance in order to meet the power and round-trip efficiency requirements for the electric vehicle applications. The characteristics of the NEC Supercaps show a large increase (1-2 orders of magnitude) in energy density beyond that of previously available low voltage capacitors, but their resistance is much too high for the EV applications. Hence the challenge of developing high energy density capacitors (ultracapacitors) for EVs is to increase the energy density to at least $5 \mathrm{Wh} / \mathrm{kg}$ and at the same time maintain an acceptably low resistance. The maximum permissible value of resistance, expressed as ohm$\mathrm{cm}^{2}$, depends on the $\mathrm{F} / \mathrm{cm}^{2}$ and voltage of the cell. For $1 \mathrm{~F} / \mathrm{cm}^{2}$ and $1 \mathrm{v} / \mathrm{cell}$, the value of ohm- $\mathrm{cm}^{2}$ should be $<0.1$. In addition, the cycle life of the devices should be 1-2 hundred thousand charge/discharge cycles and the initial cost must be affordable. Projections of future development given in the literature (Reference 7) for mixed-oxide ultracapacitors indicate that the performance goals can be met and surpassed in a few years. Meeting the goals for carbon-based devices is expected to be more difficult, but the cost of the carbon-based capacitors is at the present time projected to be much less ( at least a factor of ten) than that of the mixed-oxide devices, which presently utilize ruthenium and tantalum oxides as key materials. 


\section{CONCLUSIONS AND RECOMMENDATIONS FOR FUTURE WORK}

\section{Conclusions}

1. The programmable test equipment in the INEL Battery Laboratory can be used to characterize high energy density capacitor devices utilizing test procedures appropriate for electric vehicle applications.

2. Both carbon-based and mixed-oxide capacitor devices appear to offer considerable promise for load leveling the batteries in electric vehicles. The devices tested had energy densities of 1 to $2 \mathrm{Wh} / \mathrm{kg}$ and could be discharged at power densities up to $1.5 \mathrm{~W} / \mathrm{kg}$. The capacitance of the devices in discharge are rate dependent with the dependency of the carbon-based devices being much higher than that of the mixed-oxide devices.

3. The capacitors can sustain for 5 to 7 hours a PSFUDS cycle consisting of repeated charge/discharge segments with an average charge/discharge period of approximately 30 seconds. The usable energy in the capacitor for discharge, between the rated and one-half the rated voltage, is about one-half that stored in the capacitor when it is charged from 0 to the rated voltage.

4. The efficiencies of the capacitors for the PSFUDS cycle were between 75 to $85 \%$. The efficiency values from electrical data agreed to within 2 to 3 points with values obtailed from thermal tests utilizing a simple, calibrated calorimeter.

5. Life-cycle tests of the capacitor devices, using a simple charge/discharge cycle, indicated a cycle life of over 100,000 cycles can be expected for such devices. 


\section{Recommendations for future Work}

1. Characterization of high-energy density capacitor devices should continue as larger devices become available from various sources around the world.

2. An R\&D program to develop capacitor devices with energy densities of at least $5 \mathrm{Wh} / \mathrm{kg}$ for electric vehicle applications should be supported by the Department of Energy (DOE). The results of the present study indicate that the basic characteristics of the high-energy density capacitors are attractive for electric vehicles, but the energy density of available devices are too low, by a factor of 3 to 4 . The increase in energy density must be attained without a large increase in resistance.

3. Work to incorporate the capacitors into electric vehicle drivelines should be started, including the development of interface electronics to accommodate the large voltage change in the capacitors as they are charged and discharged. This voltage variation is at least a factor of two.

4. Consideration should be given to the utilization of high-energy density capacitors to other vehicle applications, including preheating catalytic converters for exhaust emission reduction and load leveling the heat engine in a hybrid electric vehicle to improve fuel economy. 


\section{REFERENCES}

1. Burke, A.F., Hardin, J.E., and Dowgiallo, E.J., Application of Ultracapacitors in Electric Vehicle Propulsion Systems, Proceedings of the 34th Power Sources Symposium, Cherry Hill, N.J., June 25-28,1990

2. Burke, A.F. and Dowgiallo, E.J., Evaluation of Pulse Power Devices in Electric Vehicle Propulsion Systems, Proceedings of the 10th Inteinational Electric Vehicle Symposium, Hong Kong, December 3-5, 1990

3. Burke, R.F. and Cole, G.H., Simulation of Electric Vehicles with Hybrid Power Systems, Proceedings of the 10th International Electric Vehicle Symposium, Hong Kong, December 3-5,1990

4. Tanaka, T., and etals, Electric Double Layer Capacitors: FYH and FYD Series Supercapacitors, NEC Research and Development, No.92, January 1989

5. Rowand, D., The Super Capacitor--A New Back-up Power Source, New Electronics, 21 July 1987

6. Product Specification Sheets received from NEC Electronics, Mountain View, California 94043

7. Projections of the Performance of U1tracapacitors (1990-94), News Release from Pinnacle Research Institute, September 1990 

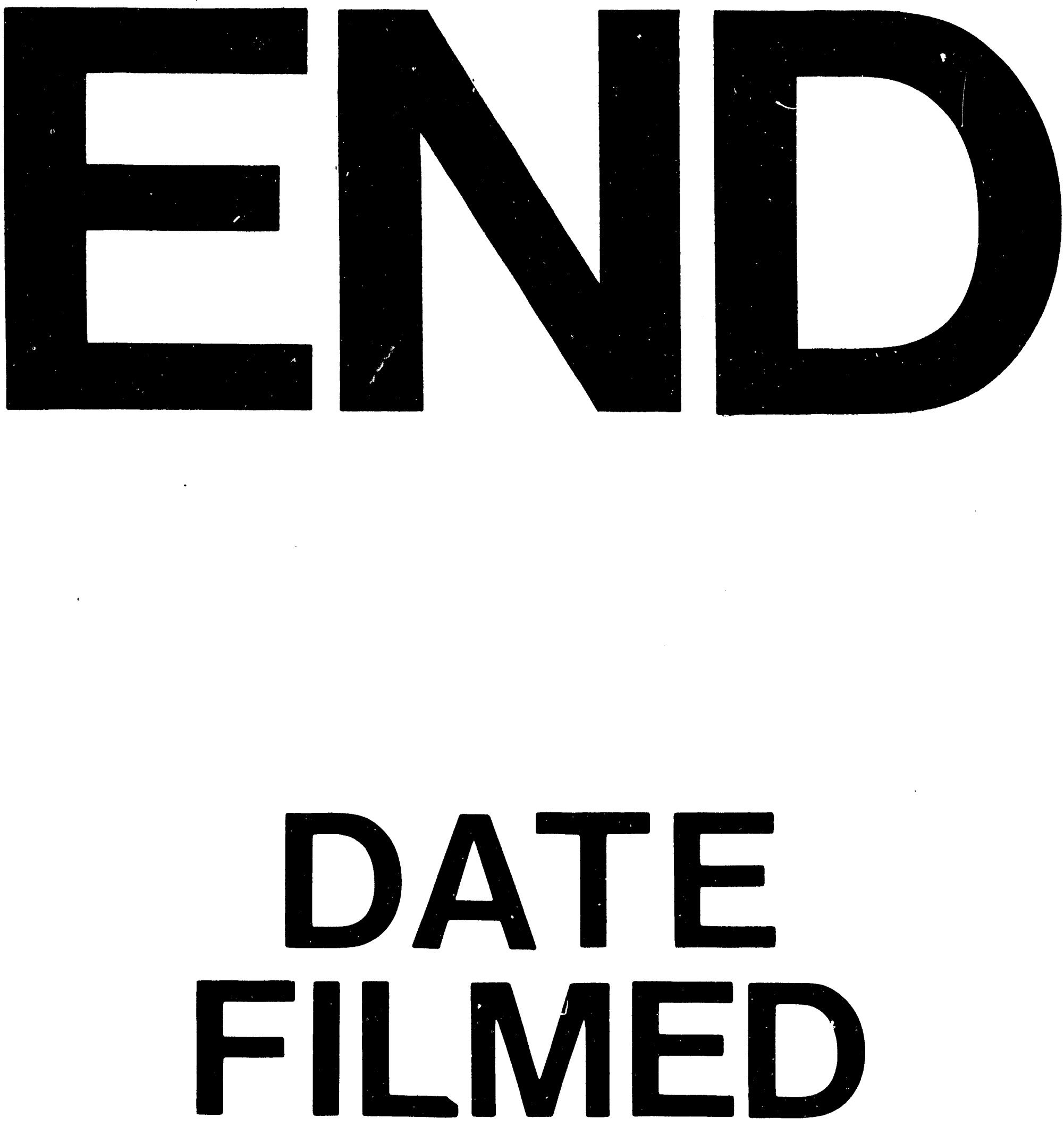

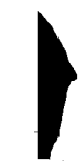

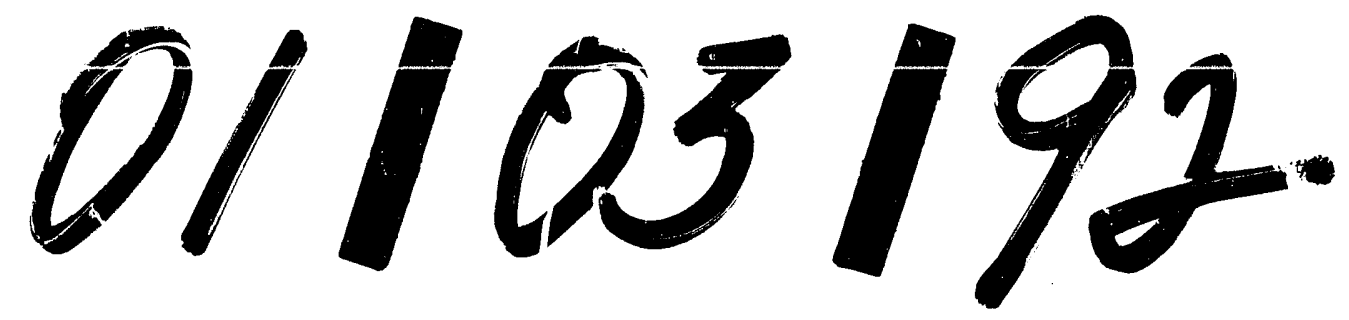

$-1$ 